\title{
COMBINING BRAZILIAN TESTS ON MASONRY CORES AND \\ DOUBLE PUNCH TESTS FOR THE MECHANICAL
}

CHARACTERIZATION OF HISTORICAL MORTARS

\author{
Diego Marastoni ${ }^{a}$, Luca Pelà ${ }^{\text {b* }}$, Andrea Benedetti ${ }^{a}$, Pere Roca ${ }^{b}$ \\ ${ }^{a}$ Department of Civil, Chemical, Environmental and Materials Engineering, University of Bologna, Viale \\ Risorgimento 2, 40136 Bologna, Italy. \\ ${ }^{b}$ Department of Civil and Environmental Engineering, Technical University of Catalonia (UPC- \\ BarcelonaTech), Jordi Girona 1-3, 08034 Barcelona, Spain.
}

\begin{abstract}
This research presents a novel integrated methodology for the experimental characterization of historical mortars, including different types of laboratory tests. Different experimental tests on lime mortar brickwork were carried out, including Brazilian tests on core drilled masonry samples with one diametral mortar joint and double punch tests on extracted mortar joints. By representing the mortar's state of failure on the Mohr's plane for the different tests, it is possible to estimate the material's strength envelope through a least square minimization method. The proposed approach can be useful to evaluate the compressive, tensile and shear behaviour of mortar in existing structures.
\end{abstract}

Keywords: Historical masonry, Lime Mortar, Coring, In-situ Sampling, Minor Destructive Testing (MDT), Brazilian Test, Double Punch Test (DPT), Mohr-Coulomb theory, Shear strength, Failure Envelope.

\section{Highlights:}

- Novel MDT for mechanical characterization of mortar in existing masonry structures

- Core-drilling of brick and lime mortar masonry walls using dry (no water) procedure

- Brazilian tests on cores varying the inclination of the diametral mortar joint 
- Novel micromechanical model for joint interpretation of DPT and Brazilian tests

- The model provides reliable estimation of mortar's mechanical parameters

\section{Introduction}

The experimental characterization of existing masonry is still a challenging task due to the large possible combinations of material components, their complex mechanical behaviour and the difficulties related to testing and sampling techniques. The evaluation of the mechanical properties of masonry in historical buildings is often made difficult by the need to minimize the damage caused during the inspection. Samples extracted from the buildings should be sufficiently small so as to cause a minimum disturbance, preserve the original material and avoid risks and difficulties linked to the alteration of structural members.

Clay bricks and lime mortar are normally the most common components in historical buildings of the built heritage. In Italy, for instance, this has been confirmed by several studies based on chemical analysis conducted on a large portion of the Italian territory [1] and more recently on the areas struck by the 2012 Emilia-Romagna earthquake [2].

As for the experimental characterization of the material components (mortar and units), the current standards only consider tests made on standard specimens that are mainly intended for new structures, like whole units or prismatic specimens of mortar $[3,4]$.

Binda and co-workers [5,6] conducted experimental campaigns on new masonry components to evaluate their main mechanical properties, working on standard prismatic specimens of clay brick and either hydraulic or aerial lime mortar. The studies showed the intrinsic difficulties related to the experimental estimation by laboratory testing of important parameters like Young's modulus, Poisson's ratio, compressive and tensile strengths. Standard tests were carried out, like compression on bricks and three-point bending and compression tests on mortar, following the available technical standards [7-9]. 
Standard tests considered by technical regulations are hardly applicable to existing masonry structures. They are in fact only applicable to bricks, since entire units or sufficiently large brick samples may be extracted without deteriorating excessively the masonry member. On the other hand, the difficulties related to the analysis of historical mortars even arise from the extraction of undisturbed and appropriate specimens. The standard tests on prismatic mortar specimens are practically impossible, since only thin mortar joints can be extracted from the existing masonry. Recent studies showed the issues related to non-standard testing of irregular samples of historical mortars $[10,11]$. Besides the mechanical characterization of elastic and strength properties, it is usually necessary to evaluate also the shear behaviour of existing masonry, especially in seismic prone countries. In-situ diagonal compression tests [12] are rather expensive and usually inappropriate for historical constructions, since the structure normally cannot be excessively damaged during the testing activities.

In most cases, a preferable alternative seems the adoption of Minor Destructive Testing (MDT), also in possible combination with Non-Destructive Testing (NDT). Among the MDT procedures, an interesting possibility is the extraction of small specimens to be tested in laboratory. This methodology is appropriate for historical constructions, since samples can be extracted from hidden structural members reducing to the minimum the amount of induced damage. Recent studies showed the possibility of in-situ core drilling, perpendicular to the face of the structural member, to extract masonry cylindrical samples to be tested in the laboratory [13-15]. This sampling technique does not induce excessive damage to the historical structure and it allows a direct estimation of the mechanical properties by testing the core specimens in the laboratory. The cores include two circular segments of brick and a diametral mortar joint, with a total diameter of the sample from 70 to $110 \mathrm{~mm}$. The cylindrical samples are tested according to a new layout for the Brazilian test, with the diametral mortar joint inclined with respect to its original horizontal position in the wall. Such special testing setup induces to the mortar in the joint a stress state of simultaneous normal compression and tangential shear. Different combinations of shear-compression stresses can be applied to the mortar joint by varying the diametral joint inclination. 
This last improvement of the experimental technique led to the derivation of more information from the tests than in previous studies [16,17], where the Brazilian tests were carried out with a fixed inclination of the mortar joint of $45^{\circ}$. In these studies from the nineties, the authors were mostly interested in obtaining a relationship between the shear strength of the joint and those of medium (triplets) and big (walls) assemblages of cement mortar masonry. In case of Brazilian tests of cores with $45^{\circ}$ inclined joint, they assumed that the load split into normal and tangential components on the mortar joint. This led to the hypothesis of infinitesimal thickness of the mortar joint, reducing it to a non-dimensional interface between the bricks.

On the other hand, Benedetti and co-workers [18] proposed an alternative interpretation of the stress state inside the diametral mortar joint of the cylindrical specimen, by considering the whole mortar layer, instead of reducing it to an interface. In this case, it was possible to introduce into the mechanical interpretation of the test also the mutual interaction between the two circular segments of brick and the mortar in the joint. Such interaction induces a three-dimensional state of stress to the mortar. The graphical interpretation of each test requires the drawing of Mohr's circles representing the complete stress state in the mortar at failure. Most recent experimental studies by the same authors [13-15] showed the possibility of carrying out different Brazilian tests by varying the inclination of the diametral mortar joint. In this way, different shear-compression states can be applied to the mortar, corresponding to different Mohr's circles on the Mohr's plane. The Mohr's circles related to the Brazilian tests were complemented with those corresponding to compression tests on the mortar, e.g. using the Double Punch Test (DPT). Finally, all the Mohr's circles representing mortar at failure under different stress conditions were used to derive the Mohr's failure envelope by means of a least square method.

All the aforementioned studies about Brazilian tests on cores with inclined diametral joint showed that the mode of failure of the specimen is strongly dependent on the type and strength of mortar. In case of lowstrength lime mortar, the failure was characterized in most cases by a fracture crossing the mortar joint at the core's centre and involving the upper and lower brick-mortar interfaces at the sample extremities (combined sometimes with detachment of a small brick wedge close to the load), see Fig. 1a. This mode of failure was 
called "parasymmetric" or "centrally symmetric" [13] and it was observed in experimental programs carried out with low-strength mortars, like in [13] with lime mortar with compressive strength of $1.9 \mathrm{MPa}$, and in [16] with lime-cement mortar with compressive strength from 1.8 MPa to 2.5 MPa. These ranges of strength values are actually representative of the behaviour of typical low-strength historical mortars. For higher strength mortars, different types of failure were observed. Failures resulting from either splitting of the core or pure shear sliding along the brick-mortar interface (Fig. 1b) were observed in [19], with a cement-lime mortar with higher strength of 7.8 MPa, that could be hardly considered representative of a low-strength historical mortar. Other experimental results presented in [16] also showed an almost vertical crack, splitting the bricks parallel to the load direction (Fig. 1c), for a high-strength cement mortar.

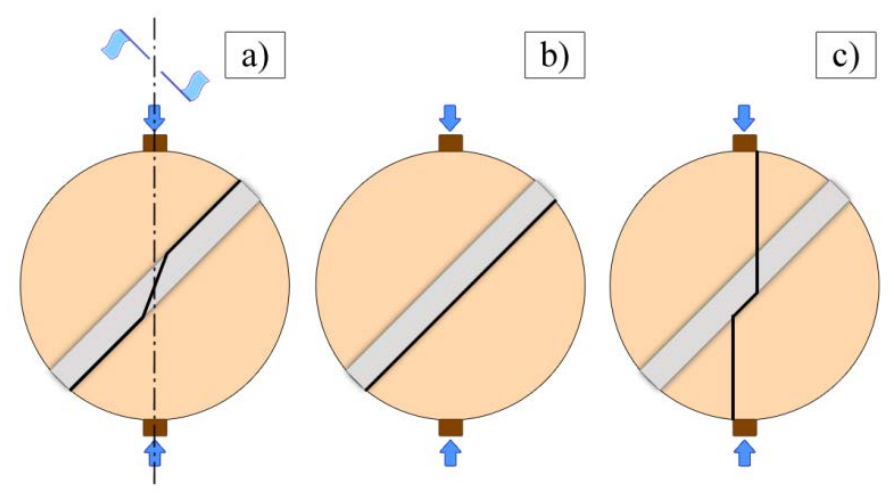

Fig. 1 Modes of failure observed in Brazilian tests on cores with inclined diametral joint: a) "parasymmetric” or "central symmetric” fracture [13] for low-strength mortars; b) shear sliding along the brick-mortar interface [19] and c) splitting failure [16,19] for higher strength mortars.

This paper presents an experimental program intended to reproduce in the laboratory the MDT of historical masonry by means of in-situ sampling and subsequent laboratory testing of small specimens. Proper material components were chosen in order to reproduce those typically employed in historical masonry with low mechanical properties, i.e. handmade clay bricks and lime mortar. The manufacturing and curing of lime mortar were carefully executed using traditional building techniques in controlled laboratory conditions. Each material 
component was tested in order to obtain a comprehensive characterization of its mechanical behaviour. Then, the selected materials were used to build two masonry walls. After the necessary period of curing and hardening to reach a sufficient strength of the material, the extraction of cylindrical samples was carried out by core drilling. A novel dry extraction procedure, based on an air cooling system, was adopted as an alternative to common wet core drilling in which water could spoil the lime mortar joints in the samples. Brazilian tests were carried out on $90 \mathrm{~mm}$ diameter masonry cores by varying the inclination of the diametral mortar joint with respect to its original horizontal position. DPTs were also executed on mortar joints extracted from the same walls. A comprehensive micromechanical interpretation of the different experimental tests is presented. Finally, an integrated methodology is proposed to obtain a full characterization of the mechanical properties of mortar, considering the redundant results derived from all the different types of experimental tests executed. A meaningful contribution of the study is the proposal of a failure criterion for mortar based on Mohr's parabolic law, as well as an alternative simplified linear model based on Mohr-Columb theory with tension cut-off. The experimental procedures adopted, as well as the theory proposed for the interpretation of the tests, can be considered during the inspection activities on historical masonry structures to evaluate the mechanical properties of the existing mortar.

\section{Experimental program}

The experimental investigation was carried out at the Laboratory of Technology of Structures and Materials of the Technical University of Catalonia (UPC-BarcelonaTech). In the following, each stage of the experimental program is discussed in detail, paying attention to important issues like the preparation of material samples, the curing conditions, the procedures of extraction and testing.

\subsection{Materials}

Handmade fired-clay solid bricks were used in this experimental program, with nominal dimensions of $305 \times$ $145 \times 45 \mathrm{~mm}^{3}$. The units presented some voids and imperfections, due to their hand-moulded nature. 
Cement mortars were used starting from the $20^{\text {th }}$ century and could not be used to represent the behaviour of historical mortars. Lime-cement mortars are often adopted in laboratory experimental programs in order to reduce the curing times compared to a pure-lime mortar, but they usually provide higher strengths that those normally found in historical masonry structures. In this work, a moderately hydraulic lime mortar was employed to obtain a closer representation of an historical material, despite the longer time necessary for its hardening.

The mortar was mixed starting from the raw components. The river sand had $0 \div 2 \mathrm{~mm}$ grain size. The full description of the granulometry is reported in Fig. 2. Moderately natural hydraulic lime (NHL), classified as NHL 3.5 by EN 459-1 [8], was utilized. The volume ratio of binder to aggregate was 1:3, a rather typical mix in historical masonry [20].

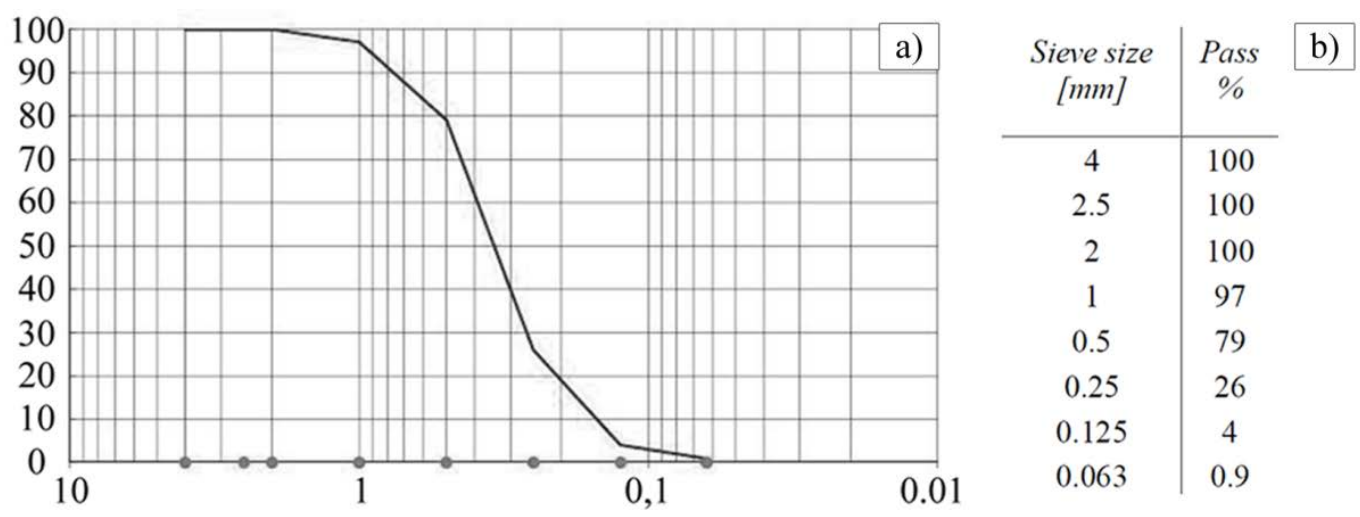

Fig. 2 Sand grain size: cumulative curve (a) and granulometry (b).

Once the mortar was prepared, two single-leaf walls were built in stretcher bond with final dimensions $1.6 \times 0.8$ $\times 0.145 \mathrm{~m}^{3}$. The external thickness of the joints was variable from 15 to $20 \mathrm{~mm}$, due to the imperfect faces of the handmade bricks. The wall was built over a steel beam to ease its displacement during the following stages of the experimental campaign. The walls were stored in the laboratory for 60 days, allowing the mortar to harden until reaching a sufficient strength to represent the behaviour of a low-strength mortar historical masonry wall. 


\subsection{Mechanical characterization of materials}

Due to the lack of a specific standard for the evaluation of the tensile strength of bricks, the EN 1015-11:2007 standard for mortars [7] was used as a reference. Six $40 \times 40 \times 160 \mathrm{~mm}^{3}$ prisms were cut (Fig. 3a) and tested according to a three-point bending setup. The average experimental flexural strength was $3.63 \mathrm{MPa}$ with a CV of $4 \%$. Cubic specimens of about $35 \times 35 \times 35 \mathrm{~mm}^{3}$ were cut from the bricks (Fig. 3b) and provided an average compressive strength of $18.40 \mathrm{MPa}$, with a CV of $6 \%$.

Since there are no available standards for the laboratory evaluation of the Young's modulus of the brick, the EN 12390-13:2013 [9] for concrete samples was considered as a reference. Three cylinders were cored from the header face of the brick with a diameter of $35 \mathrm{~mm}$ and length of $75 \mathrm{~mm}$ (Fig. 3c). The upper and lower faces were rectified to make them parallel and then the samples were tested using extensometers to measure the vertical deformation of the central third. The Young's modulus was estimated considering three loading cycles from $10 \%$ to $30 \%$ of the failure load. The average value was $9792 \mathrm{MPa}$ with a CV of $20 \%$. The higher scatter may be justified by the heterogeneity of the hand-made bricks employed in the research. 


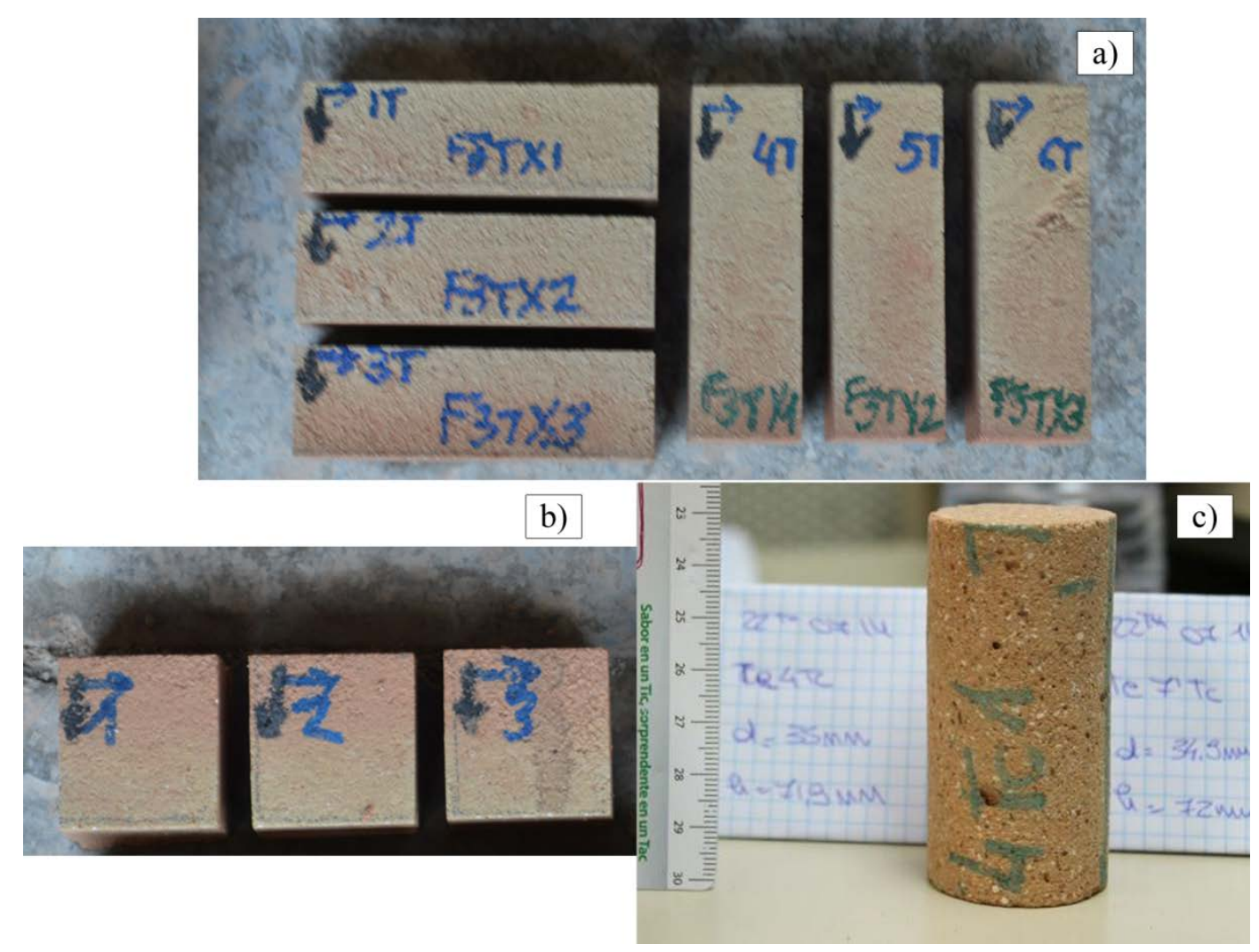

Fig. 3 Brick specimens: prisms for three-point bending test (a), cubes for compression test (b) and cylindrical sample for Young's modulus evaluation (c).

Similar tests were performed on mortar specimens prepared in metal moulds at the same time of the construction of the walls. Three $40 \times 40 \times 160 \mathrm{~mm}^{3}$ prisms (Fig. 4a) were tested 270 days after their construction to determine the flexural tensile strength $f_{t m, f}$ and the compressive strength $f_{c m}$, according to EN 1015-11:2007 [7]. The average value of the flexural tensile strength was $0.37 \mathrm{MPa}$ with a CV of $7 \%$. The compression tests were conducted on the six fragments produced by the flexural tests. The six remaining pieces measured roughly $40 \times 40 \times 80 \mathrm{~mm}^{3}$ and were loaded with steel loading platens of $40 \times 40 \mathrm{~mm}^{2}$. The average compressive strength was $2.45 \mathrm{MPa}$ with a CV of $8 \%$. 


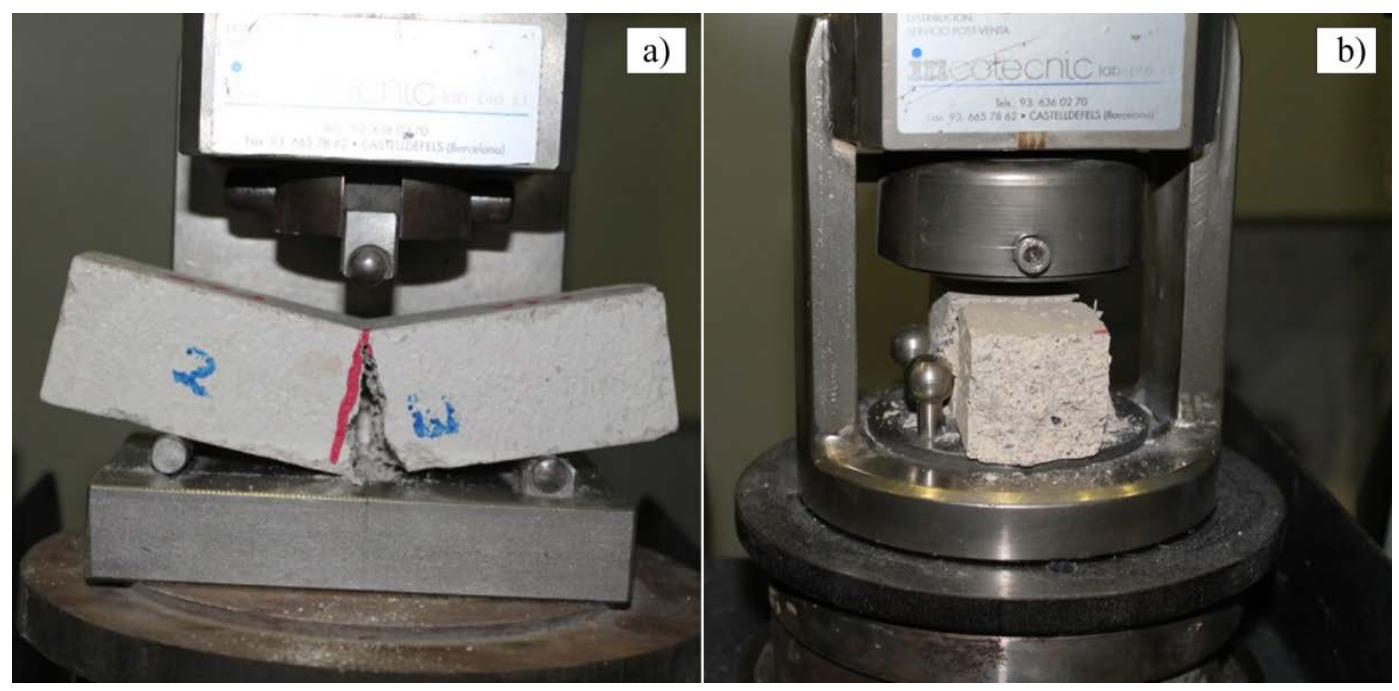

Fig. 4 Three-point bending test (a) and compression test (b) on mortar prisms.

\subsection{Extraction of cylindrical specimens}

The extraction of cylindrical specimens from the two walls was carried out 60 days after their construction. The walls were maintained in vertical position during the coring operations (Fig. 5a). During the movements, a proper confinement was ensured by two horizontal steel profiles, placed below the base and the over the upper edge and connected by four rods tensioned by a small force (Fig. 5b).

Horizontal core drilling was executed perpendicularly to the face of the walls (Fig. 5b) using a 90 mm diameter core bit. A novel procedure was followed in order to avoid spoiling the samples during their extraction. Common core drills, normally adopted for concrete structures, use a water cooling system. This well-known system showed its limitations in previous experimental programs, since water could wash lime mortar joints away [13]. In addition, the use of water can be inconvenient in case of sampling activities from the inside of existing historical buildings. For this reason, this research proposes a novel dry extraction procedure, in which air cooling is adopted instead of water cooling, in order to preserve the integrity of the mortar joints. Air cooling is ensured by an aspirator connected to the coring bit. However, during the masonry core drill, the dust might block the sample inside the bit. In fact, the bit usually overheats during drilling, allowing the dust to 
interpose between itself and the sample. As soon as the core drill stops working and the bit gets colder, its sudden contraction might block the specimen inside. The aspirator continuously removes the dust inside the bit and cools down the system, but sometimes its effect is not sufficient. Therefore, in this study, the masonry was core drilled step by step, making sure that at each small step the dust was removed completely either by the aspirator or by a spray compressor. By using this procedure, a total of 22 intact cores were extracted for this experimental program. In addition, other 30 larger diameter cores were extracted from the walls, without any operational problem, and they were utilized for a different research study.

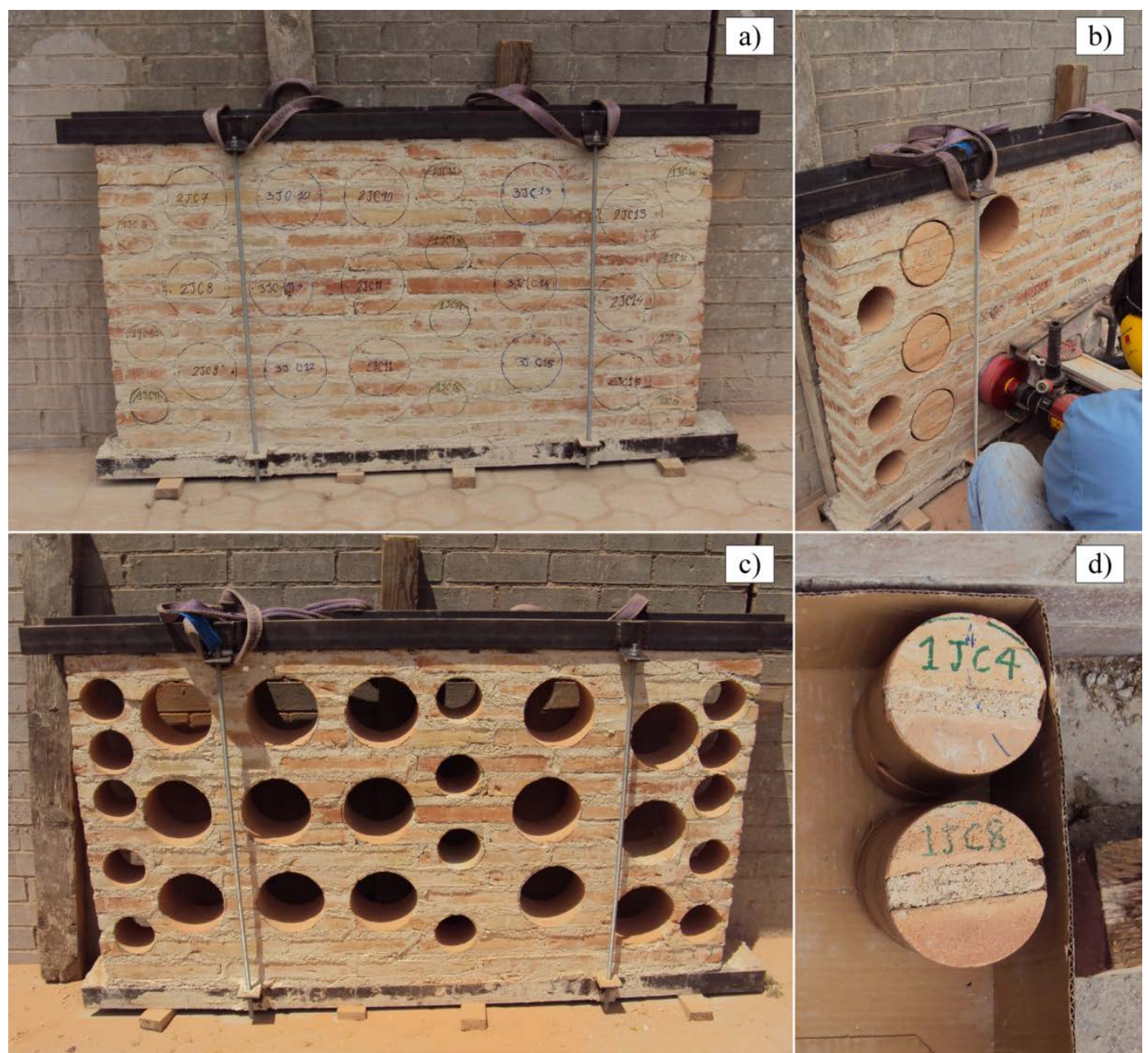

Fig. 5 Masonry walls before (a), during (b) and after coring (c) and some samples extracted (d). 
After the extraction of the core samples (Fig. 5d), the remains of the two walls shown in Fig. 5c were dismantled to extract mortar layers. The mortar layers were carefully detached from the bricks using a thin chisel, in order to obtain small mortar samples for the double punch tests. Every mortar sample was cut to obtain square-shaped specimens, with a side of about $50 \mathrm{~mm}$ and variable thickness between 10-20 mm. The thickness of each sample depended on the thickness of the original mortar joint in the wall.

\section{Experimental testing of the specimens extracted from the walls}

This section presents the results from the testing procedures used for the mechanical characterization of the mortar in the walls. In order to simulate the procedures to be followed during an in-situ experimental campaign, Brazilian Test (BT) of masonry cores with inclined diametral mortar joint and Double Punch Test (DPT) of mortar layers were performed.

\subsection{Brazilian tests on cores with inclined diametral mortar joint}

The samples that were core drilled from the walls were subject to BTs [13-15] after 210 days from the extraction. In this experimental program the specimens were tested with the diametral mortar joint inclined at $45^{\circ}, 50^{\circ}, 55^{\circ}$ and $60^{\circ}$ with respect to the original horizontal direction. A wooden strip was interposed between the metallic plates and the sample in order to distribute uniformly the loading over the irregular lateral surface of the core. All the tests were performed with a compression machine with vertical displacement control and a $200 \mathrm{kN}$ load cell. The setup of the test was studied to avoid the separation of the specimen after the failure by placing two soft horizontal supports avoiding in any case spurious confinement effects. The test was conducted under vertical displacement control at a $4 \mu \mathrm{m} / \mathrm{s}$ rate. The relative sliding displacement between the two bricks was measured with high precision LVDTs (range $\pm 1.5 \mathrm{~mm}$, precision $\pm 1.5 \mu \mathrm{m}$ ) at both circular faces (Fig. 6a and Fig. 6b). The acquisition frequency was $50 \mathrm{~Hz}$ due to the high fragility of the failure process. 

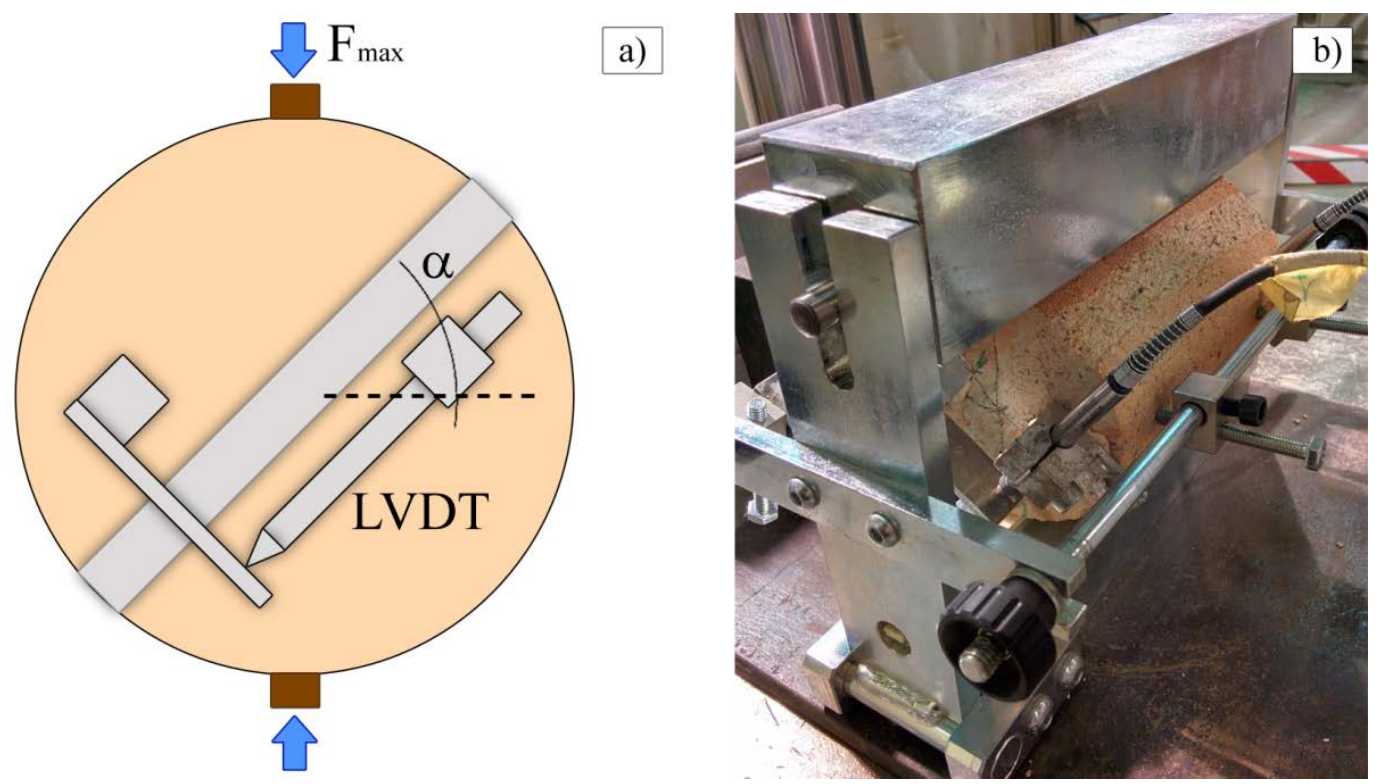

Fig. 6 Brazilian test on cores with inclined mortar joint: experimental setup (a) and specimen during the test (b).

The diametral mortar layer included between two circular segments of brick is subject to normal compression and tangential shear due to the vertical loading applied during the test. BTs were executed over 14 samples obtained according to the aforementioned extraction procedure. The 14 samples showing the best geometrical regularity after core-drilling were selected for BTs. In most of the specimens analysed in this experimental program, the failure was characterized by a fracture crossing the mortar joint in the centre of the specimen and also interesting the upper and lower unit-mortar interfaces at the extremities (Fig. 1a). Such kind of failure was called "parasymmetric" or "central symmetric" in a previous study by the authors [13]. The observed parasymmetric failures resulted in remarkable agreement with those observed in previous studies on lowstrength mortar masonry [13-17]. The crack sometimes appeared also in the bricks, involving a small wedge under the loading area. A small part of the specimens experienced a different failure mechanism, i.e. sliding along the brick-mortar interface that might have been activated by local imperfections and heterogeneities in the material. Fig. 7 reports a summary of the crack patterns obtained in all the specimens. 


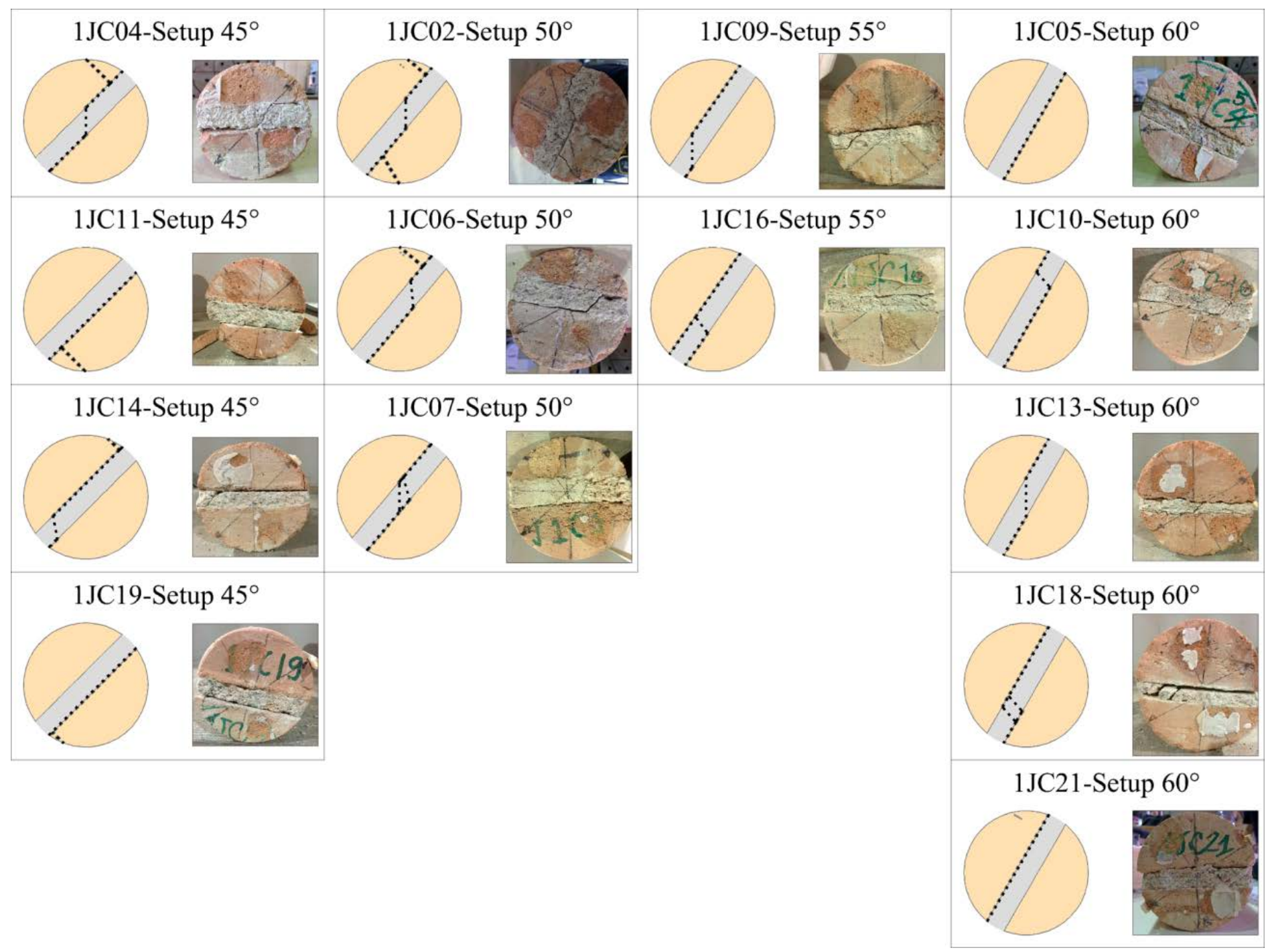

Fig. 7 Brazilian tests on cores with inclined mortar joint: types of failure in all the core samples.

Fig. 8 shows the curves of the experimental load vs. joint's relative displacement that were obtained from all the BTs. The displacement controlled tests provide more relevant information than the force controlled ones. Consequently, it was possible to obtain the post-peak softening branch describing the nonlinear behaviour of the material. However, the execution of a displacement controlled BT is a complex task due to the remarkable brittleness of mortar material. Due to the fragile behaviour of the experimental response, it was impossible to record continuously the post-peak phase in all the investigated samples. 

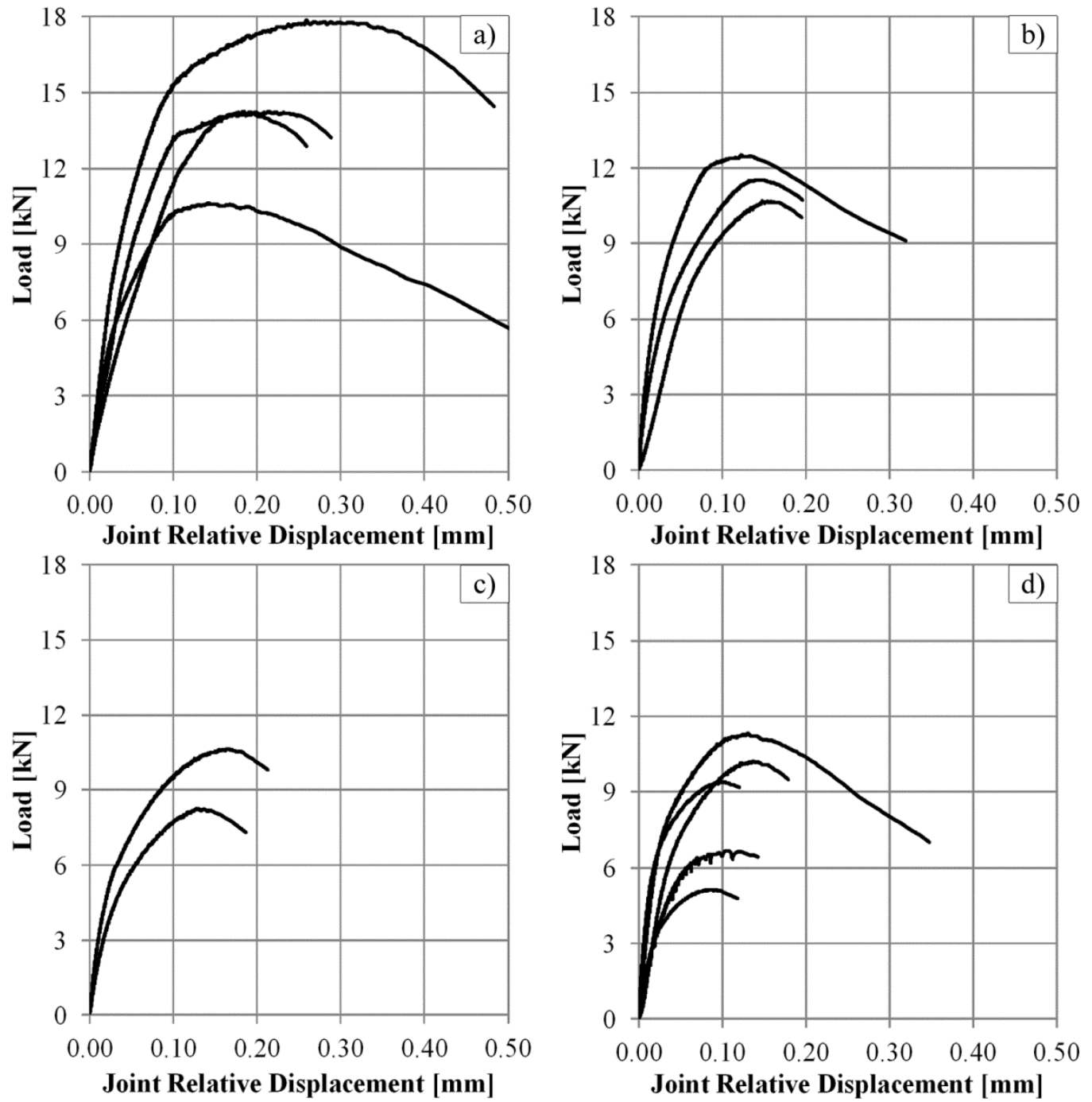

Fig. 8 Brazilian tests on cores with inclined mortar joint: curves of load vs. joint's relative displacement for $\alpha=45^{\circ}$ (a), $50^{\circ}$ (b), $55^{\circ}$ (c), $60^{\circ}(\mathrm{d})$.

The stress state in the mortar joint at failure of the sample, according to [13-15], can be evaluated by means of Equations 1a,b:

$\sigma_{\max }=\frac{F_{\max }}{A} \cdot \cos (\alpha) \quad \tau_{\max }=\frac{F_{\max }}{A} \cdot \sin (\alpha)$ 
where $\sigma_{\max }$ is the normal compression in the joint, $\tau_{\max }$ is the tangential shear stress in the joint, $F_{\max }$ is the maximum experimental load, $A$ is the area of the mean section of the mortar joint (i.e. product between the diameter and length of the core sample) and $\alpha$ is the angle of inclination of the mortar joint with respect to the horizontal direction (Fig. 9). Equations 1a,b are simple expressions based on the assumption of a homogenous redistribution of the stresses over the mortar joint.

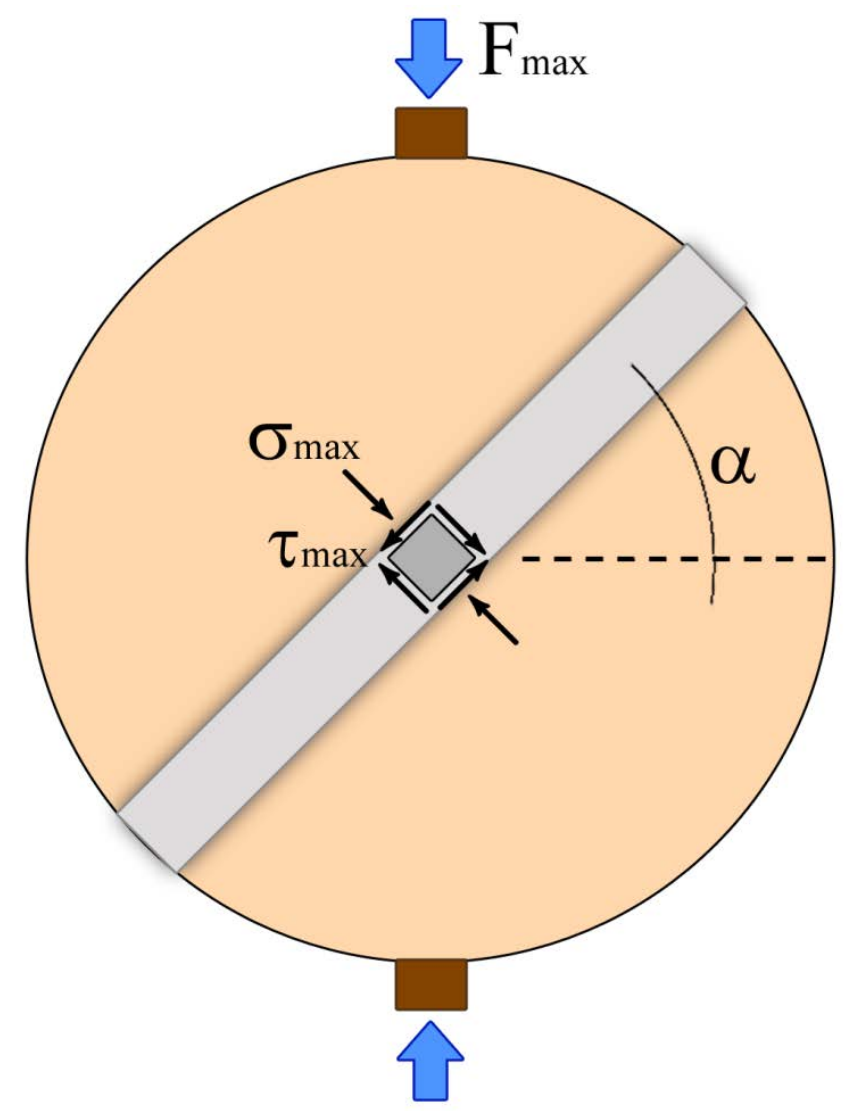

Fig. 9 Brazilian tests on cores with inclined mortar joint: state of stress at failure.

Table 1 presents the summary of the experimental values at failure that were obtained from all the BTs for different inclinations of the diametral mortar joint. The mean values of the failure loads show a descending trend with the increase of the angle $\alpha$, in accordance with previous studies [13,14,19]. For instance, the average failure load decreases from $14.23 \mathrm{kN}$ for $\alpha=45^{\circ}$ to $8.54 \mathrm{kN}$ for $\alpha=60^{\circ}$. This is due to the increasing ratio 
between the tangential shear and normal stresses acting on the mortar joint as $\alpha$ increases. The variability of the

CVs in Table 1 shall be related to the failure mechanisms obtained in each group of samples with the same inclination of the diametral mortar joint. For instance, the lowest CV for the failure load is that for $\alpha=50^{\circ}(8 \%)$ since all the samples showed the parasymmetric failure. On the other hand, the highest CV was given by $\alpha=60^{\circ}$ (30\%) since three out of five samples showed the parasymmetric failure, while the other two samples experienced pure sliding. In the authors' experience, the extraction and preparation of specimens to be tested is very important in order to minimize the dispersion of BT results. For this reason, key factors are the regularity of the mortar joints in the cylindrical samples as well as the care devoted to the core drilling operations.

Table 1 Experimental results of Brazilian tests on masonry cores with inclined mortar joint.

\begin{tabular}{ccccc}
\hline Sample & $\alpha{ }^{\circ}{ }^{\circ}$ & $\mathbf{F}_{\max }[\mathbf{k N ]}$ & $\boldsymbol{\sigma}_{\max }[\mathbf{M P a}]$ & $\boldsymbol{\tau}_{\max }[\mathbf{M P a}]$ \\
\hline $1 \mathrm{JC} 04$ & 45 & 10.62 & 0.56 & 0.56 \\
$1 \mathrm{JC} 11$ & 45 & 14.19 & 0.76 & 0.76 \\
$1 \mathrm{JC} 14$ & 45 & 17.87 & 0.95 & 0.95 \\
$1 \mathrm{JC} 19$ & 45 & 14.26 & 0.76 & 0.76 \\
$1 \mathrm{JC} 02$ & 50 & 12.50 & 0.58 & 0.69 \\
$1 \mathrm{JC} 06$ & 50 & 11.53 & 0.55 & 0.66 \\
$1 \mathrm{JC} 07$ & 50 & 10.68 & 0.52 & 0.61 \\
$1 \mathrm{JC} 09$ & 55 & 10.63 & 0.46 & 0.66 \\
$1 \mathrm{JC} 16$ & 55 & 8.25 & 0.36 & 0.51 \\
$1 \mathrm{JC} 05$ & 60 & 5.12 & 0.19 & 0.33 \\
$1 \mathrm{JC} 10$ & 60 & 9.39 & 0.35 & 0.61 \\
$1 \mathrm{JC} 13$ & 60 & 11.32 & 0.42 & 0.73 \\
$1 \mathrm{JC} 18$ & 60 & 10.20 & 0.39 & 0.67 \\
$1 \mathrm{JC} 21$ & 60 & 6.69 & 0.26 & 0.45 \\
\hline$A v g 45^{\circ}$ & 45 & 14.23 & 0.76 & 0.76 \\
$C V \% 45^{\circ}$ & & $21 \%$ & $21 \%$ & $21 \%$ \\
\hline$A v g 50^{\circ}$ & 50 & 11.57 & 0.55 & 0.66 \\
$C V \% 50^{\circ}$ & & $8 \%$ & $6 \%$ & $6 \%$ \\
\hline$A v g 55^{\circ}$ & 55 & 9.44 & 0.41 & 0.58 \\
$C V \% 55^{\circ}$ & & $18 \%$ & $18 \%$ & $18 \%$ \\
\hline$A v g 60^{\circ}$ & 60 & 8.54 & 0.32 & 0.56 \\
$C V \% 60^{\circ}$ & & $30 \%$ & $30 \%$ & $30 \%$ \\
\hline & & & & \\
\hline
\end{tabular}


A previous experimental work available in the literature presented an attempt to evaluate the shear elastic modulus $G_{m}$ from shear tests on triplets [21]. This idea was reconsidered in this work in order to study a possible method for estimating $G_{m}$ from BTs of core samples. In fact, the assessment of $G_{m}$ might be possible after having measured the relative displacement between the brick circular segments due to the shear elastic deformation of the mortar joint. Considering the initial elastic response of mortar, the shear elastic modulus can be estimated as the ratio between the tangential stress $\tau$ and the shear strain $\gamma$. The evaluation of $G_{m}$ depends on the stress/strain level at which it is calculated. Technical recommendations available in the literature do not provide any suggestion for the assessment of $G_{m}$. For this reason, it was found interesting to measure the variability of $G_{m}$ values for different elastic stress levels. The tangential stress can be defined similarly to Equation 1a but for a load level lower than that at failure, i.e. still within the elastic range of mortar. The load level to be considered for the evaluation of $G_{m}$ can be expressed as a percentage of the maximum failure load according to $\beta \cdot F_{\text {max }}$, where $0<\beta<1$. The shear strain is the deformation over the thickness of the joint. The shear elastic modulus is finally determined by Equation 2 as:

$G_{m}=\frac{\beta \cdot \tau_{\max }}{\gamma}=\frac{\beta \cdot F_{\max }}{A} \cdot \sin (\alpha) \cdot \frac{t}{\delta}$

where $t$ is the thickness of the mortar layer and $\delta$ is the relative displacement measured between the two circular segments of brick at the load $\beta \cdot F_{\max }$. 


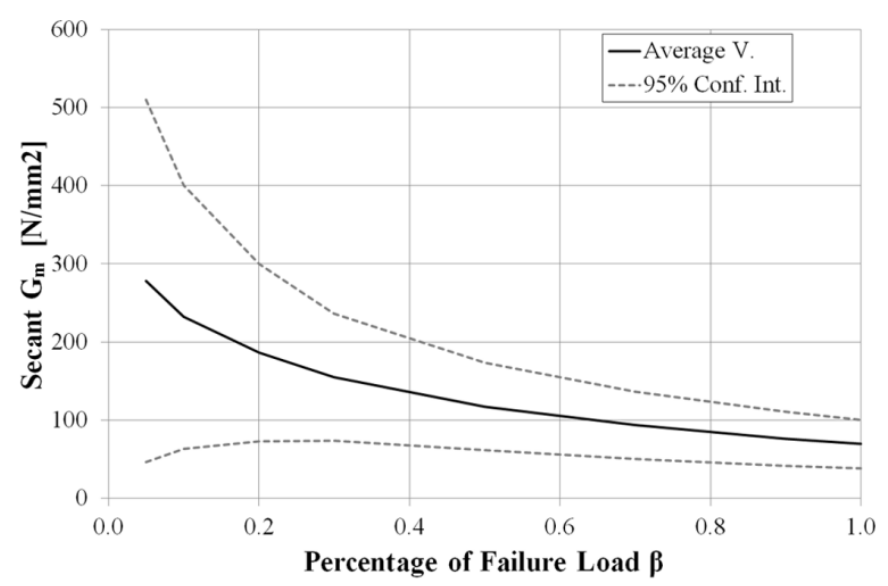

Fig. 10 Secant shear modulus vs. elastic stress level.

Fig. 10 shows the experimental law of variation of the mean secant $G_{m}$ for different elastic stress levels. The mean values of secant $G_{m}$ were obtained by averaging all the results from BTs on cores with different inclinations of the mortar joint. The continuous line indicates the mean values of the secant $G_{m}$ corresponding to different values of $\beta$ parameter, i.e. to different elastic stress levels before the maximum experimental load ( $\left.\beta=1, F=F_{\max }\right)$. The dotted lines define the 95\% confidence interval, considering a normal (Gaussian) distribution. As shown, the experimental scatter around the mean secant tangential modulus is rather large for low values of $\beta$. This is due to the initial settlement of mortar in the core samples at the beginning of the loading test. After $\beta=0.3$ the scattering reduces remarkably (CV is around $25 \%$ ) and maintains a narrow variation until the failure load. Therefore, this study shows that the shear elastic modulus $G_{m}$ shall be evaluated at least at the $30 \%$ of the maximum experimental load in order to obtain reliable results. The post-processing of the experimental data from this research provided a shear elastic modulus of mortar $G_{m}=154 M P a$.

It is important to underline that, in principle, the relative displacement between the bottom and upper surfaces of the mortar joint includes both the shear (elastic) deformation of mortar and the shear slips of the two contact surfaces between brick and mortar. Given the experimental type of failure (Fig. 1a) and the realistic magnitudes 
of the $G_{m}$ values obtained in the present research, it was acceptably assumed that the most of the deformation was due to the shear distortion in the mortar.

\subsection{Double punch tests on mortar joints}

The DPT is a promising MDT technique that revealed to be suitable for the mechanical characterization of mortar in existing masonry structures [14,15]. It consists in a local compression test performed on roughly $50 \times$ $50 \mathrm{~mm}^{2}$ mortar layers using two special punching devices with a contact surface diameter of $20 \mathrm{~mm}$ (Fig. 11a). Being mortar a heterogeneous material and being the DPT executed on a small portion of the mortar layer, the experimental results usually present high scatter. In addition, the upper and lower faces of the mortar joint, once detached from the bricks during sampling, appear normally irregular. This drawback adds a further complexity to the DPT. However, DPT can provide useful information about the strength of mortar and is actually the only possible laboratory test that can be carried out on mortar samples extracted from existing masonry structures.

The DPTs were conducted following the DIN 18555-9:1999 standard [21] and relevant references [14,15,22], using a compression machine equipped with a force controlled $10 \mathrm{kN}$ load cell.

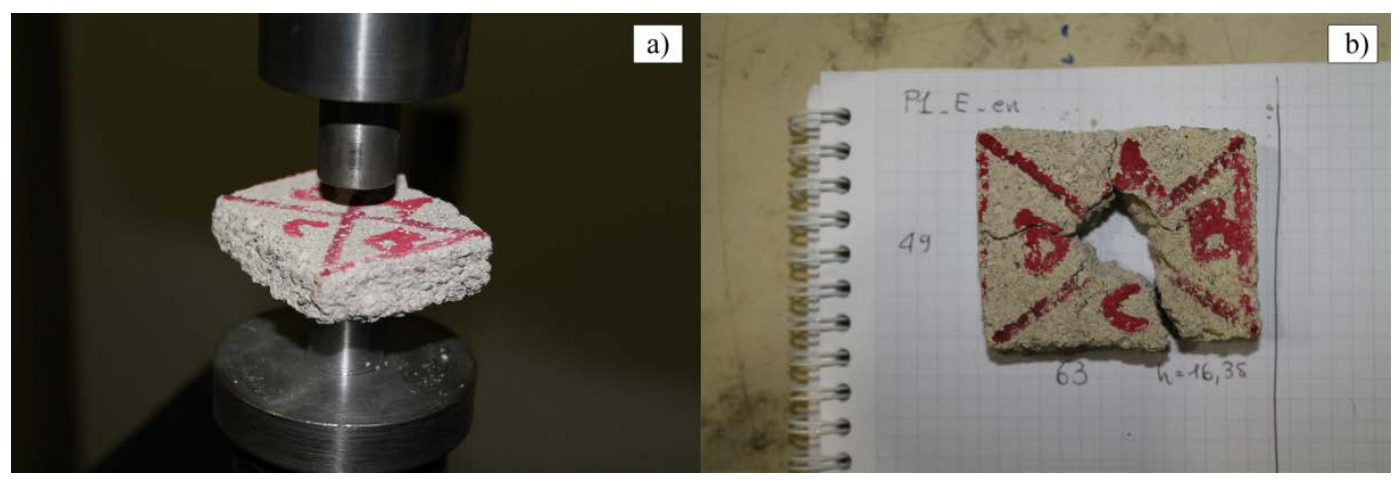

Fig. 11 Double punch test of mortar joints before (a) and after failure (b) 
The compressive strength from DPT is calculated by Equation 3:

$\sigma_{\max }=\frac{F_{\max }}{\pi r^{2}}$

where $F_{\max }$ is the maximum experimental load and $r=10 \mathrm{~mm}$ is the radius of the tested surface. The DPT can hardly be considered as a simple uniaxial compression stress test. In fact, the sample is highly confined due to its small thickness, the friction with the punches and the presence of external material surrounding the loaded area. The stress state induced by DPT on the specimen seems to be actually triaxial. This phenomenon is confirmed also by the failure mode of the specimen (Fig. 11b), where the surrounding material exhibits radial cracks arising from the area under the punches. These cracks are due to the confinement exerted by mortar surrounding the loading area. A discussion about the interpretation of the experimental data from DPT is included in the next section. Table 2 shows a summary of the results obtained from this experimental program.

Table 2 Experimental results of double punch tests on mortar joints.

\begin{tabular}{cc}
\hline Sample & $\boldsymbol{\sigma}_{\max }$ [MPa] \\
\hline P1_E & 2.29 \\
P2_E & 2.91 \\
P3_E & 2.29 \\
P4_E & 3.41 \\
P5_E & 3.04 \\
P2_E_2 & 2.60 \\
P3_E_2 & 2.38 \\
P4_E_2 & 3.40 \\
P5_E_2 & 2.10 \\
\hline Average & 2.71 \\
CV\% & $18 \%$
\end{tabular}

\section{Interpretation of the experimental results}

This section presents the comprehensive discussion and interpretation of the results from the BTs on masonry cores with inclined diametral mortar joint and the DPTs on mortar joints. The tests considered in this experimental program are analysed in depth to estimate the properties of mortar. A novel micromechanical 
interpretation of the experimental results from BT and DPT is proposed. Finally, the combination of all the parameters obtained during the post-processing of the tests leads to the development of an integrated method for the evaluation of mortar's mechanical properties starting from the redundant information from different kinds of tests.

\subsection{Interpretation of Brazilian tests on cores with inclined diametral mortar joint}

The mechanical interpretation of the experimental results from BTs is carried out firstly using continuum mechanics theory. The mortar joint is not seen as an interface but as a continuum subject to a triaxial state of stress during the execution of the BT. This kind of interpretative approach was called Continuum Model in [13] and was firstly proposed in $[14,15,18]$. Further improvements to the model are presented in this study together with its validation by comparison with experimental results obtained in the laboratory.

According to the Continuum Model, the state of stress in the mortar joint during the BT can be represented graphically in the $\sigma-\tau$ Mohr's plane by means of Mohr's circles. The circles representing the mortar's stress state at failure are tangent to the failure envelope. A Mohr-Coulomb criterion represented by a straight line was considered in [13]. The parameters $c$ and $\phi$ of the criterion, denoting the material's cohesion and friction angle, were determined using a least square method in order to best fit the experimental data set.

This paper presents an improvement to the aforementioned approach, since it considers a more realistic nonlinear Mohr's criterion as failure envelope for the Mohr's circles of the BTs at failure (see Section 4.4). In addition, this work considers a more precise graphical representation of the stress state by Mohr's circles based on the representation of the complex triaxial state of stress actually experienced by the mortar during the BT. Fig. 12 shows the comparison between the Mohr's circle representation of a generic BT as done in previous works $[13-15,18]$ and in the present one. The former is drawn using a light grey line, whereas the second is drawn in dark grey. The stress state inside the mortar joint at failure is also presented, referring to Fig. 9 and Equations 1a,b. As shown, the previous researches considered, as an approximation, zero confinement in the direction parallel to the joint. This hypothesis is reinterpreted here by including also the confinement effect $\sigma_{H}$ 
in the Mohr's representation. This confinement is exerted by the stiffer circular segments of brick that limit the expansion of the softer diametral mortar joint during the execution of the BT. The graphical representation of this effect implies the construction of a smaller Mohr's circle than in the case of zero confinement (see Fig. 12). Notice that compression stresses are considered positive in Fig. 12 and also in the following ones.

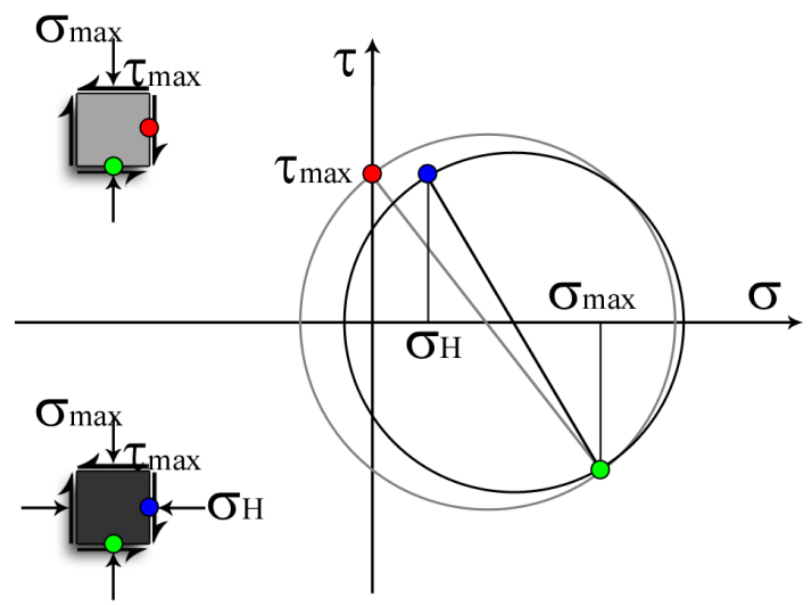

Fig. 12 Continuum model. Mohr's circle representations of the failure stress state in the mortar joint during the Brazilian test: unconfined (grey, [13-15,18]) vs. confined conditions (black).

Hilsdorf's theory about masonry in compression [23] is considered to estimate the magnitude of the confinement stress $\sigma_{H}$. Hilsdorf's assumption of elastic behaviour of material's components prior to failure leads to a compatibility condition providing the confinement ratio $K_{H}$ (Equation 4):

$K_{H}=\frac{\sigma_{H}}{\sigma_{\max }}=\frac{v_{m}-\frac{E_{m}}{E_{b}} \cdot v_{b}}{1-v_{m}+\left(1-v_{b}\right) \cdot \frac{E_{m}}{E_{b}} \cdot \frac{h_{m}}{h_{b}}}$

where $v_{m}$ and $v_{b}$ are the Poisson's coefficients of mortar and bricks, $E_{m}$ and $E_{b}$ the Young's moduli of mortar and bricks, $h_{m}$ and $h_{b}$ the thicknesses of the mortar joint and the bricks. 
The complete stress state in the mortar joint at failure is eventually defined using the following Equations 5a,b,c. instead of those given in Equations 1a,b that did not consider the confinement effect [13-15].

$\sigma_{\max }=\frac{F_{\max }}{A} \cdot \cos (\alpha) \quad \sigma_{H}=K_{H} \cdot \sigma_{\max } \quad \tau_{\max }=\frac{F_{\max }}{A} \cdot \sin (\alpha)$

Table 3 presents the estimated values of the confinement stresses $\sigma_{H}$ for each BT and thus complements the experimental results presented in Section 2.2 for their post-processing and interpretation. The confinement ratio resulted $K_{H}=0.415$, having assumed in calculations the following average parameters: $E_{m}=400 M P a$, $E_{b}=9792 \mathrm{MPa}, v_{m}=0.30, v_{b}=0.17, h_{m}=15 \mathrm{~mm}$ and $h_{b}=77 \mathrm{~mm}$. The material's parameters that were not directly assessed by the experimental tests presented in the previous section were assumed on the base of previous works by the authors and reference values available in the literature. The Young's modulus of mortar $E_{m}$ was evaluated by the authors in another experimental program employing the same material, using cylindrical samples with $75 \mathrm{~mm}$ diameter and $150 \mathrm{~mm}$ height. The values of both $E_{m}$ and $v_{b}$ are in agreement with those derived from previous experimental studies $[1,5,24]$ on materials similar to those investigated in the present research, i.e. lime mortar and clay bricks. The value of $v_{m}$ was derived using the theory of elasticity with the assumed value of $E_{m}$ and the value $G_{m}=154 \mathrm{MPa}$ that was estimated from the experimental tests in Section 3.1. 
Table 3 Estimation of the confinement stress $\sigma_{H}$ for the mechanical interpretation of the Brazilian tests.

\begin{tabular}{ccc}
\hline Sample & Angle $\left[{ }^{\circ}\right]$ & $\boldsymbol{\sigma}_{\boldsymbol{H}}[\boldsymbol{M P a}]$ \\
\hline 1JC04 & 45 & 0.23 \\
1JC11 & 45 & 0.32 \\
1JC14 & 45 & 0.40 \\
1JC19 & 45 & 0.32 \\
\hline 1JC02 & 50 & 0.24 \\
1JC06 & 50 & 0.23 \\
1JC07 & 50 & 0.21 \\
\hline 1JC09 & 55 & 0.19 \\
1JC16 & 55 & 0.15 \\
\hline 1JC05 & 60 & 0.08 \\
1JC10 & 60 & 0.14 \\
1JC13 & 60 & 0.17 \\
1JC18 & 60 & 0.16 \\
1JC21 & 60 & 0.11 \\
\hline
\end{tabular}

An alternative interpretative approach to the BTs was proposed in [13] and called Interface model. In this second model, the mortar joint is analysed as a zero-thickness diametral interface that separates the core sample in two halves [16]. The state of stress in the interface is described by only two components, i.e. the normal and tangential stresses $\sigma$ and $\tau$, see Fig. 13. Failure of mortar is understood as shear sliding on this joint interface. The stress state at failure of each BT is represented by a point in the $\sigma-\tau$ plane whose coordinates are provided by Equations 1a,b. Due to the modelling of the mortar joint as an interface instead of a continuum, this model does not account for the triaxial stress state in the mortar joint at failure.

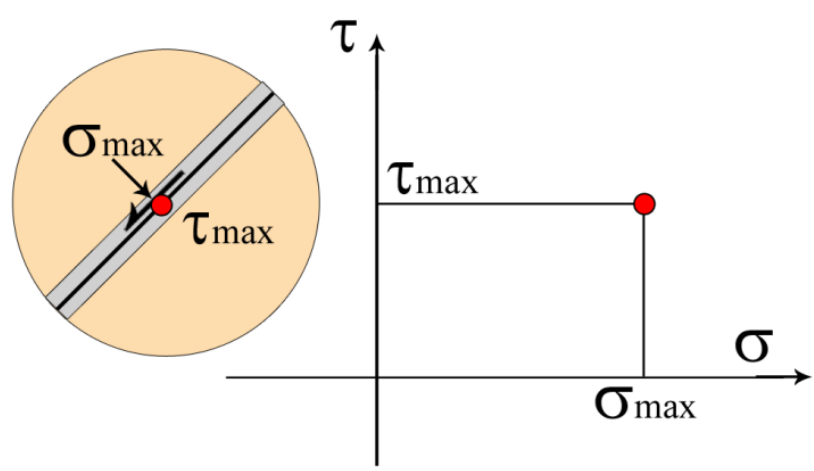

Fig. 13 Interface model: mortar’s stress state at failure from the Brazilian test. 


\subsection{Interpretation of Double Punch Test}

A precise interpretation of the DPT results requires the estimation of the transversal confinement exerted by the loading punches on the flat sample of mortar. This is necessary in order to obtain a more precise graphical presentation by Mohr's circles of the stress states in DPTs. The Hilsdorf's theory [23] reported in Section 4.1 is not suitable for DPT, since the hypothesis of constant horizontal stresses along the joint depth is not valid due to the fact that the dimensions of the metal punches are comparable to the thickness of the mortar specimen.

The analysis of the transversal confinement in the mortar sample was carried out by means of a numerical simulation of the DPT using a Finite Element Model (FEM). The FEM was elastic and its only purpose was to evaluate the amount of horizontal confinement to which the mortar joint sample is subject during the DPT. Due to the axial symmetry of the problem, an axisymmetric analysis was carried out by discretizing only the radial cross-section of the real DPT. The FEM model included, besides the $10 \mathrm{~mm}$ radius punches, the $15 \mathrm{~mm}$ thick mortar sample with a radius of $25 \mathrm{~mm}$ that corresponds to the radius of the cylinder inscribed into the real prismatic specimen. The mesh was composed of 36601 nodes and 12000 eight-node plane elements (Fig. 14a). The mortar's Young's modulus was $E_{m}=400 \mathrm{MPa}$ and the Poisson's ratio was $v_{m}=0.30$. The Young's modulus of metallic punches was $E_{s}=200000 \mathrm{MPa}$ and the Poisson's ratio was $v_{s}=0.25$. The values for mortar were estimated on the basis of the experimental results, while typical values were adopted for the steel. Fig. 14b shows the evolution of the ratio between the horizontal and vertical stresses $\left(\sigma_{H} / \sigma_{V}\right)$ obtained by the FEM analysis. The graphs show the laws of variation of the confinement ratio between the punches along different sections. As shown, the horizontal stress in the central section of the mortar sample can be estimated as $5 \%$ of the vertical pressure. 

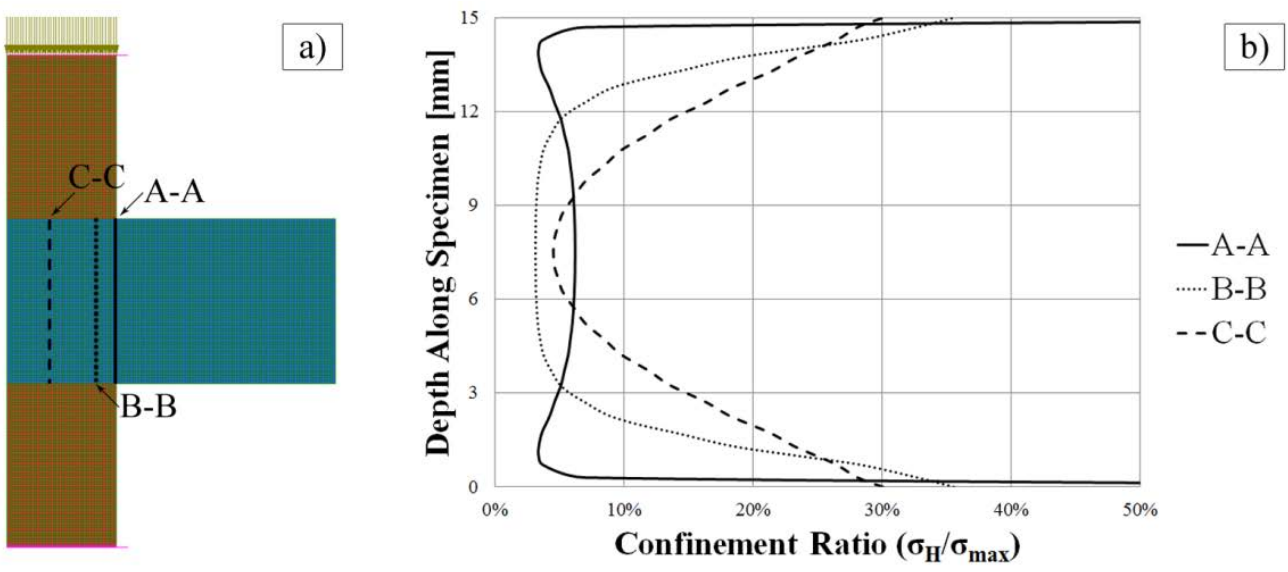

Fig. 14 Axisymmetric FEM model of DPT (a) to evaluate the confinement ratio between the punches (b).

After the FEM analysis, it was possible to draw with precision the Mohr's circle representing the stress state at failure of the mortar sample in the DPT. Instead of considering a uniaxial compression stress state, graphically represented by a Mohr's circle tangent to the vertical $\tau$ axis, this research proposes to consider also the effect of the confinement and thus the Mohr's circle is shifted away from the $\tau$ axis (Fig. 15). The stress state representative of the failure of a mortar joint sample during DPT is finally estimated by means of the following equations:

$\sigma_{\max }=\frac{F_{\max }}{A} \quad \sigma_{H}=0.05 \cdot \sigma_{\max } \quad \tau=0$ 


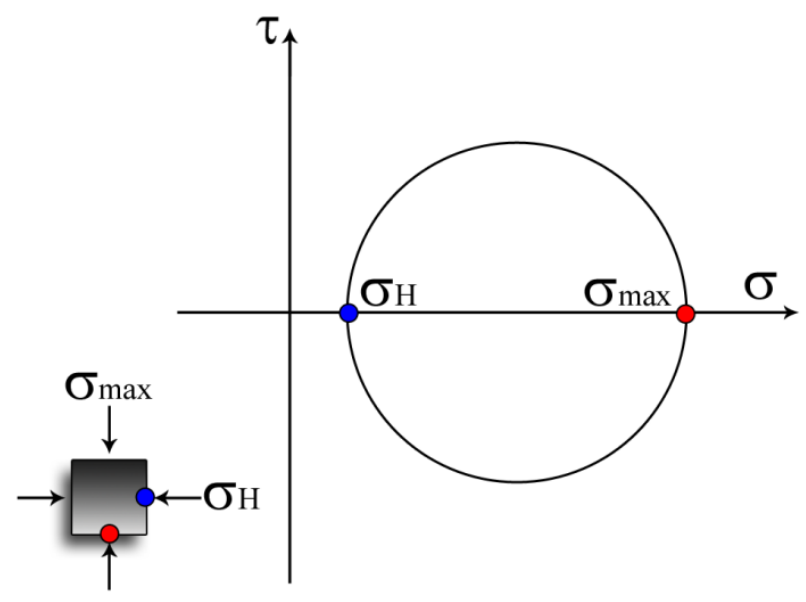

Fig. 15 DPT confined stress state and Mohr’s circle.

Table 4 presents the estimation of the horizontal confinement stress $\sigma_{H}$ for each DPT of this experimental program, under the hypotheses assumed in Equations 6a,b,c.

Table 4 Estimation of the confinement stress $\sigma_{H}$ in double punch tests on mortar joints.

\begin{tabular}{cc}
\hline Sample & $\boldsymbol{\sigma}_{\boldsymbol{H}}[\boldsymbol{M P a}]$ \\
\hline P1_E & 0.12 \\
P2_E & 0.15 \\
P3_E & 0.11 \\
P4_E & 0.17 \\
P5_E & 0.15 \\
P2_E_2 & 0.13 \\
P3_E_2 & 0.12 \\
P4_E_2 & 0.17 \\
P5_E_2 & 0.11 \\
\hline
\end{tabular}

\subsection{Continuum model for the evaluation of mortar's properties from Brazilian and Double Punch Tests}

An integrated method is proposed to post-process the experimental results from BTs and DPTs and to evaluate the properties of mortar. The continuum model presented in Section 4.1 represents graphically the mortar's state of stress at failure by Mohr's circles in the $\sigma-\tau$ Mohr's plane. The failure criterion can be represented 
by the envelope of all the Mohr's circles. The experimental results are usually scattered due to unavoidable heterogeneities in the mortar joints. For this reason, the failure envelope must be assessed by adopting a statistical approach leading to the determination of the best fit over the group of circles. A previous study by the authors [13] proposed the adoption of a Mohr-Coulomb straight-line using the least squares method to minimize the sum of square distances between the line and ultimate Mohr's circles of all tested specimens. Another work [14] also used a least squares analysis on the distances between the Mohr's circles and the failure surface, but it assumed a Mohr's parabolic failure envelope. This criterion can be defined by two positive constants, $\sigma_{0}$ and $\tau_{0}$ in Equation 7, which indicate the intersections between the $\sigma-\tau$ axes and the parabola:

$\left(\frac{\tau}{\tau_{0}}\right)^{2}-\frac{\sigma}{\sigma_{0}}=1$

The use of a Mohr's curved criterion like the parabolic one seems the most accurate to approximate the experimental set of data, as shown in the following. A numerical program has been developed to automatize the least squares method and calculate the failure envelope. The input is the set of raw data obtained from the BTs and DPTs tests, such as dimensions of samples and failure loads. Starting from these input data the program associates a specific stress state to each sample, according to the hypotheses formulated in Section 4.1 and Section 4.2 and it calculates the relevant Mohr's circles. Then, the software evaluates the minimum distances between the centres of the Mohr's circles and the parabolic failure criterion. This distance must be carefully evaluated, by considering the minimum one among all the possible lines that pass through the centres of the Mohr's circles and are perpendicular to the parabola. In particular, when the centre of a Mohr's circle lays between the vertex $\left(-\sigma_{0}, 0\right)$ and a certain threshold $\left(\sigma_{c r i t}, 0\right)$ described in Equation 8 as

$\sigma_{\text {crit }}=\frac{\tau_{0}^{2}}{2 \cdot \sigma_{0}}-\sigma_{0}$

the minimum distance is the horizontal one, i.e. the point of tangency of the Mohr's circle is the vertex of the parabola (Fig. 16a). 

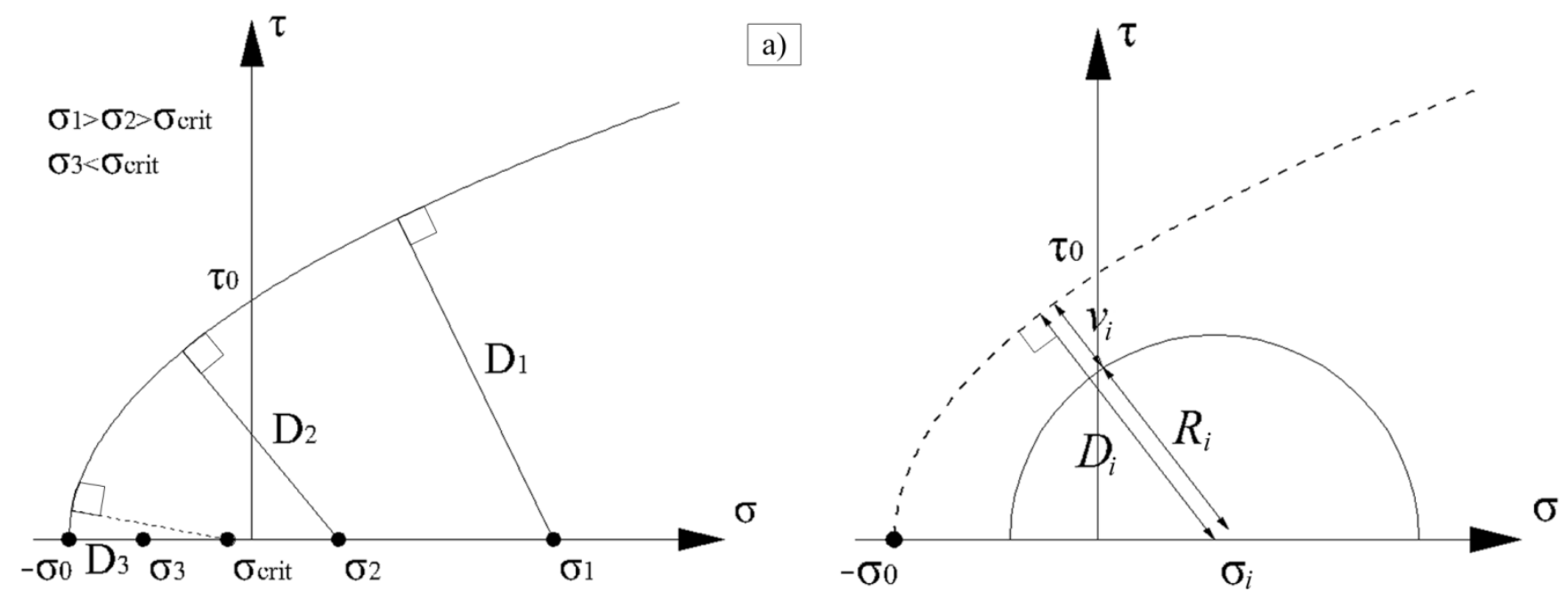

Fig. 16 Calculation of minimum distances between the centres of the Mohr's circles and the parabolic failure criterion (a) and least squares analysis used in the continuum interpretative model (b).

The distance $D_{i}$ between the centre of the $i$-th Mohr's circle $\sigma_{i}$ and the parabola can be calculated depending on its position with respect to the threshold $\sigma_{\text {crit }}$. Notice that compression stresses are considered positive both in Fig. 16a and in the following Equation 9 and Equation 10. The distance can be calculated using the following equations:

$D_{i}=\sigma_{i}+\sigma_{0}$

$$
\text { If } \sigma_{i} \leq \sigma_{\text {crit }}
$$

$D_{i}=\sqrt{\frac{\sigma_{i}+\sigma_{0}-\frac{\tau_{0}^{2}}{2 \cdot \sigma_{0}}}{\sigma_{0}} \cdot \tau_{0}^{2}+\frac{\tau_{0}^{4}}{4 \cdot \sigma_{0}^{2}}}$

$$
\text { If } \sigma_{i}>\sigma_{\text {crit }}
$$

The numerical algorithm then calculates the $\sigma_{0}$ value as the modulus of the mean principal tensile stress of the BTs with $60^{\circ}$ inclination diametral mortar joint. This choice is motivated by a good agreement between the values of the mean principal tensile stress of the BTs with $60^{\circ}$ inclination and the tensile strength provided by the flexural tests done on mortar samples, as will be remarked in the following. Such agreement indicates a 
plausible estimation of the tensile "cut-off” for the parabolic failure criterion. The flexural tests are not included in the proposal because it is based only on results obtained from nonstandard tests. Finally, a least square analysis is carried out to minimize the sum of the squared residuals $v_{i}$ obtained as the difference between the $i$ th distance $D_{i}$ and the $i$-th Mohr's circle radius $R_{i}$, as shown in Equation 11 and Equation 12, allowing to estimate the remaining parabola's parameter $\tau_{0}$ (Fig. 16b).

$v_{i}=D_{i}-R_{i}$

$\sum v_{i}^{2}=\min \rightarrow \tau_{0}$

While the tensile zone of the failure criterion is slightly nonlinear, the compressive one shows an almost linear trend. For this reason, it is interesting to compare the parabolic domain proposed in this paper with the MohrCoulomb straight one suggested in [13]. In addition, the linear domain proposed in [13] is here enriched by a tension cut-off inspired by the parabolic domain proposed in this work. Fig. 17 shows both the parabolic and the linear failure domains. The parameters obtained for the Mohr's parabolic criterion and the Mohr-Coulomb linear domain with cut-off are shown in Table 5, with reference to the experimental results from BTs and DPTs. 


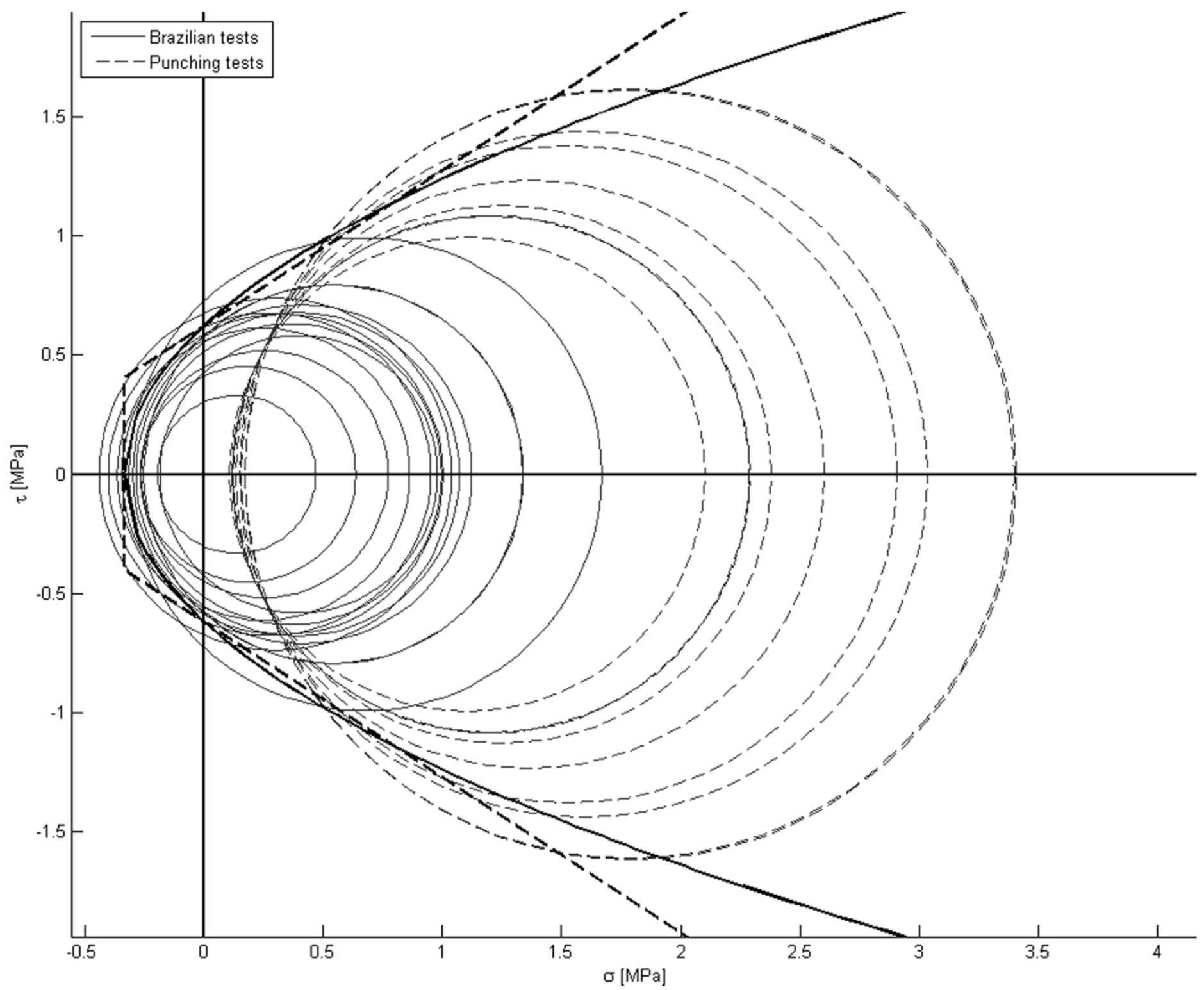

Fig. 17 Estimated parabolic Mohr's and linear Mohr-Coulomb domains obtained from DPTs and BTs.

Table 5 Parameters of the failure domains obtained from DPTs and BTs.

\begin{tabular}{lllc}
\hline \multicolumn{2}{c}{ Parabolic domain } & \multicolumn{2}{c}{ Linear domain with cut-off } \\
\hline $\boldsymbol{\sigma}_{\mathbf{0}}[\mathrm{MPa}]$ & 0.34 & $\mathbf{c}[\mathbf{M P a}]$ & 0.62 \\
$\boldsymbol{\tau}_{\mathbf{0}}$ [MPa] & 0.62 & $\boldsymbol{\varphi}\left[{ }^{\circ}\right]$ & 33.11 \\
& & $\mathbf{f}_{\mathrm{tm}}[\mathbf{M P a}]$ & 0.34 \\
\hline
\end{tabular}


As for the evaluation of the Mohr-Coulomb linear domain, the cohesion $c$ has been assumed equal to the $\tau_{0}$ parameter of the parabola, whereas the friction angle $\varphi$ has been estimated as the best-fit to the compressive part of the parabolic domain.

The proposed procedure has shown its capability in combining different testing methods (BT and DPT) to evaluate the failure envelope of mortar. Execution and comparison of different testing techniques is highly advisable during the mechanical characterization of existing materials [13-15]. The proposed approach has been then repeated including also the set of experimental results from the standard tests (flexure and compression tests on prismatic specimens according to [7]). Even though in real practice the definition of the failure domain must only be based on the BT and DPT data, since these are the only tests possible on existing structural members, the construction of a domain based on both standard and nonstandard tests is presented below as a further validation of the proposed approach.

The Mohr's circles corresponding to standard compression and flexure tests are drawn as tangent to the vertical axis of the $\sigma-\tau$ Mohr's plane, since the transversal confinement can be neglected due to the larger depth of the prismatic samples [7]. The compression and flexure tests of mortar's prismatic samples with 40 mm height would not be possible in practical studies on existing and historical structures, being possible only the extraction of core samples for BT and mortar joint layers for DPT. However, it is interesting to note that the proposed interpretative approach is rather flexible and it allows us to include the outcomes from different testing techniques. Fig. 18 and Table 5 show that the failure domains do not change so much after including also the standard tests results, compared to Fig. 17 and Table 6. This means that a remarkable agreement is found between the mechanical parameters obtained from standard laboratory tests and those derived from the proposed MDT techniques. This fact confirms that combining BTs and DPTs is a reliable method to evaluate the mechanical properties of existing mortar in historical construction. 


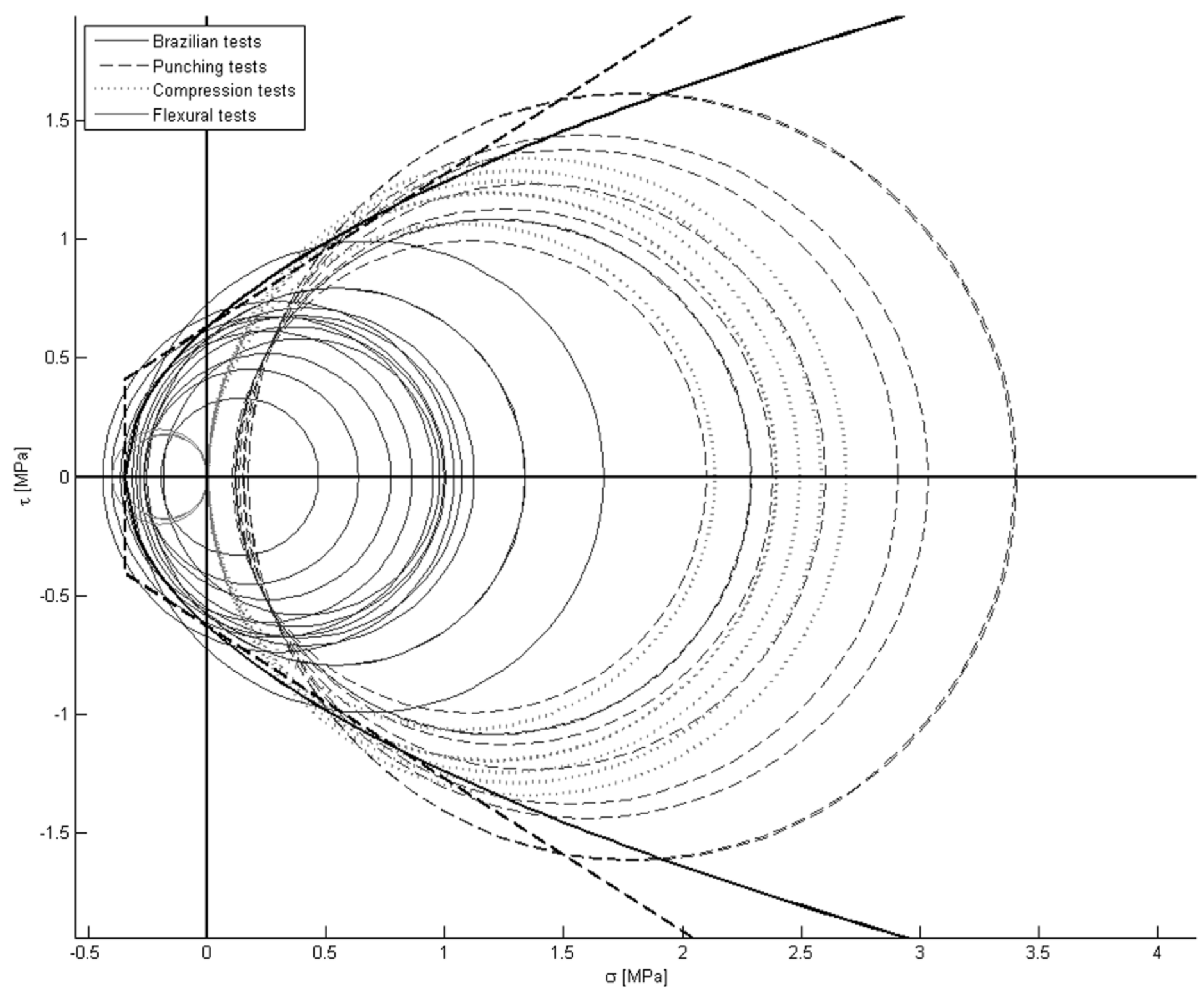

Fig. 18 Estimated parabolic Mohr’s and linear Mohr-Coulomb domains obtained from all the experimental tests (standard and nonstandard).

Table 6 Parameters of the failure domains obtained from all the experimental tests (standard and nonstandard).

\begin{tabular}{lllc}
\hline \multicolumn{2}{l}{ Parabolic domain } & \multicolumn{2}{l}{ Linear domain with cut-off } \\
\hline $\boldsymbol{\sigma}_{\mathbf{0}}$ [MPa] & 0.35 & $\mathbf{c}[\mathbf{M P a}]$ & 0.63 \\
$\boldsymbol{\tau}_{\mathbf{0}}$ [MPa] & 0.63 & $\boldsymbol{\varphi}\left[{ }^{\circ}\right]$ & 32.72 \\
& & $\mathbf{f}_{\text {tm }}$ [MPa] & 0.35 \\
\hline
\end{tabular}


The continuum interpretative model allows us also to estimate the compression strength of mortar using Equation 13, derived from Mohr-Coulomb theory:

$f_{c m}=\frac{2 \cdot c \cdot \cos (\varphi)}{1-\sin (\varphi)}$

On the other hand, the tensile strength is defined by the cut-off value $\sigma_{0}$. The mortar's compressive and tensile strengths are $f_{c m}=2.30 \mathrm{MPa}$ and $f_{t m}=0.34 \mathrm{MPa}$ for the set of experimental data including BTs and DPTs only, and they are $f_{c m}=2.32 \mathrm{MPa}$ and $f_{t m}=0.35 \mathrm{MPa}$ for the whole set of experimental data. Notice that the estimated compressive strength is only slightly lower than that directly obtained from standard compression strength on prisms $\left(f_{c m}=2.45 \mathrm{MPa}\right)$.

\subsection{Interface model for the evaluation of mortar's properties from Brazilian Tests}

The second method proposed in [13] to interpret the results from BTs on masonry cores with inclined diametral mortar joint is the interface model, already mentioned in Section 4.1. This method analyses the mortar joint as a plane interface, not explicitly accounting for the triaxial stress interaction between bricks and mortar joint. For this reason, as discussed in [13], this model seems more appropriate to describe the response of the mortar joints showing pure sliding along the brick-mortar interface (Fig. 1b) instead of the parasymmetric failure (Fig. 1a). In addition, the interface model considers the sole results from the BTs to determine the failure envelope parameters. In fact, other kinds of tests, like the DPT, cannot be included in this approach. However, the resulting model is simpler and is presented herein for the sake of comparison with the continuum model.

Each BT result is represented by a point on the Mohr's plane instead of a circle (Fig. 13). The failure envelope is determined by a linear regression of the failure points to obtain a Mohr-Coulomb criterion characterized by two parameters, the friction angle $\Phi$ and the cohesion $C$. Fig. 19 shows the failure envelope obtained from the 
experimental program considered in this research. The interface model provides a friction angle $\Phi=32.32^{\circ}$, while the cohesion is $C=0.32 \mathrm{MPa}$.

The interface model does not allow us to estimate the compression and tensile strengths of mortar. Equation 13 cannot be used to calculate $f_{c m}$ because in this approach the parameters $\Phi$ and $C$ have a different theoretical meaning.

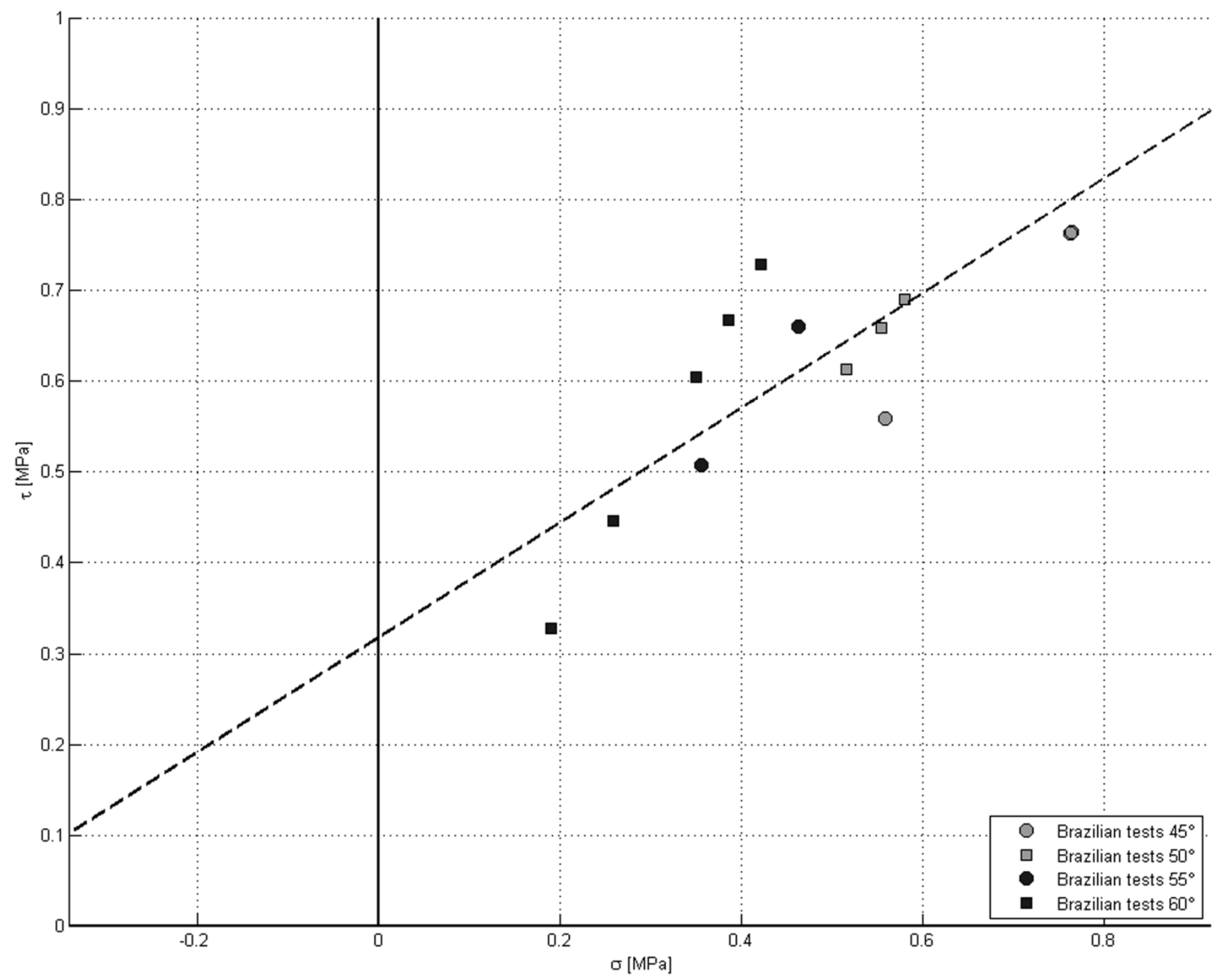

Fig. 19 Estimated linear Mohr-Coulomb domain obtained with the interface model applied to BTs. 


\section{Conclusions}

The characterization of the mechanical properties of existing mortar in historical buildings is often made difficult by the need to minimize the damage caused during the inspection. Whenever NDT methods are not possible or they should be integrated with more direct experimental tests, MDT techniques represent a feasible option. In any case, samples extracted from the buildings should be sufficiently small so as to cause a minimum of aesthetical disturbance, preserve the original material and avoid risks and difficulties linked to the alteration of structural members. Small samples can be extracted respecting the value of the construction and then brought to the laboratory to obtain a direct estimation of material's properties.

This paper has presented an experimental program aimed at developing a novel integrated methodology combining different MDT techniques to characterize historical mortar. Two one-leaf walls were built in the laboratory using handmade fired-clay solid bricks and moderately hydraulic lime mortar, to obtain masonry samples with properties similar to those of historical brick masonry. During the construction of the walls, additional prismatic specimens were prepared following the relevant standards for masonry in order to compare the proposed experimental methodology with results from standard tests. The compressive strength of brick samples was 18.4 MPa whereas the compressive strength of mortar prisms was $2.45 \mathrm{MPa}$ after 270 days of curing.

After 60 days from the construction, the walls were core drilled using a $90 \mathrm{~mm}$ diameter core bit, collecting several cylindrical specimens with a diametral mortar joint interposed between two circular segments of brick. A novel dry extraction technique was adopted for sampling by using air, instead of water, to cool the bit and to get rid of the dust. After the extraction of specimens, the walls were dismantled to collect mortar layers for DPT. After 270 days from the construction of walls, both the extracted specimens and the standard ones were tested in the laboratory. This activity provided a direct comparison between standard (compression and flexure tests of prisms) and non-standard experimental tests (BT of masonry cores with inclined diametral joint and DPT of mortar joints). 
On the basis of the results obtained from the aforementioned tests the following conclusions can be drawn:

- $\quad$ The dry extraction performed in the experimental program has shown to be more suitable for historical masonry than the water-cooled drilling, since weak mortars are often present and the water may spoil the specimen. None of the specimens was damaged during the dry core-drilling of the walls. The novel dry extraction procedure seems a reliable option for sampling, even from the interior of existing buildings.

- The novel experimental setup developed for the BTs with inclined mortar joint has afforded an estimation of the mortar's shear elastic modulus, besides the strength parameters. This estimation has been made possible by the use of displacement control via the LVDTs placed on both faces of the specimens. An estimation of $G_{m}=154 \mathrm{MPa}$ has been obtained by considering the secant value at $30 \%$ of the maximum load.

- The Brazilian tests were performed at different inclinations of the diametral joint $\left(45^{\circ}, 50^{\circ}, 55^{\circ}\right.$ and $60^{\circ}$ ), inducing different combinations of shear and compression to the mortar. The specimens exhibited a characteristic "parasymmetric" failure in most of the cases, with a fracture crossing the mortar joint and involving the two opposite brick-mortar interfaces. The results have shown that for $\alpha \geq 45^{\circ}$ the crack starts in the mortar layer, sometimes involving small parts of the brick near the loading area, confirming previous results by the authors [13].

- $\quad$ The compressive strength obtained from the DPTs (2.71 MPa) resulted 10\% higher than that obtained from standard compression tests on mortar prisms (2.45 MPa), due to the confinement induced by the external material surrounding the loaded area and also exerted by the punches over the flat specimen.

The interpretative theories proposed in [13], i.e. continuum model and interface model, have been used to process the results from the experimental program and to provide realistic estimations of mortar's mechanical parameters. The main outcomes from the two models, as well as the main novelties introduced by the present study, are summarized below: 
- The continuum model has been improved with a more refined micromechanical interpretation of the triaxial stress states in the samples at failure. This has allowed a more precise representation of the Mohr's circles of the experimental test on the $\sigma-\tau$ plane. As for the BT, the Hilsdorf's theory has been considered to estimate the horizontal confining stress in the mortar, providing a value of $41.5 \%$ of the transversal compression. As for the DPT, the horizontal confining stress has been estimated using the FEM, providing a value around the $5 \%$ of the vertical compression. The introduction of the confinement components has improved remarkably the definition of the Mohr's circles for BTs and DPTs. Another novel improvement to the continuum model has been the adoption of a Mohr's parabolic failure criterion. It has been adjusted using a least square method applied to the Mohr's circles obtained from the experimental tests. The parameters of the Mohr's parabolic failure envelope are $\sigma_{0}=0.34 \mathrm{MPa}$ and $\tau_{0}=0.62 \mathrm{MPa}$ in the present experimental campaign. The nonlinear envelope has been also simplified using a linear Mohr-Coulomb criterion with tension cut-off, whose constitutive parameters are $c=$ $0.62 \mathrm{MPa}, \varphi=33.11^{\circ}$ and $f_{t m}=0.34 \mathrm{MPa}$. The compressive strength has been derived using the Mohr-Coulomb theory as $f_{c m}=2.30 \mathrm{MPa}$. As reported in [13], the continuum model seems to be more suitable for historical masonry with weak mortars. Firstly, this model allows the combination of different types of test into an integrated methodology where every experimental result contributes to the better definition of mortar’s failure envelope. Secondly, the peculiar "parasymmetric” type of failure observed in BTs, with non-planar cracks spreading through the mortar joint, can be described more rigorously by the continuum mechanics theory.

- The interface model, on the other hand, considers the mortar joint as a two-dimensional interface, with the thickness of the joint collapsed in its central section. The state of stress is represented as a point instead of a circle on the $\sigma-\tau$ plane, excluding the possibility of integrating the DPTs results in the calculation of the failure envelope. Using the points from the sole BTs, a linear Mohr-Coulomb failure envelope has been calculated using a linear regression with $C=0.32 \mathrm{MPa}$ and $\Phi=32.32^{\circ}$. The 
interface model is a simpler approach, but it allows the interpretation of only the experimental results from BTs, excluding the possibility of integrating other types of test to evaluate the shear properties of mortar. In addition, it seems more adequate for high strength materials, like cement mortars, since its theory can describe the failure only as a shear sliding on a planar interface. Finally, the interface model cannot be considered to determine the compressive and tensile strength of mortar.

The proposed MDT techniques and their interpretation theories have shown their suitability for the experimental activities of mechanical characterization of historical masonry of the built cultural heritage. The proposed sampling technique can ensure limited invasivity to the existing structure. The novel integrated methodology for the processing of DPTs and BTs has shown good reliability and robustness.

\section{Acknowledgments}

This research has received the financial support from the MINECO (Ministerio de Economia y Competitividad of the Spanish Government) and the ERDF (European Regional Development Fund) through the MICROPAR project (Identification of mechanical and strength parameters of structural masonry by experimental methods and numerical micro-modelling, ref num. BIA2012-32234). The authors wish also to acknowledge the "Marco Polo” mobility programme of the University of Bologna. 


\section{References}

[1] G. Baronio, L. Binda, A. Saisi, Analisi di Malte Antiche e Comportamento di Malte Riprodotte in Laboratorio, in: $7^{\circ}$ Convegno Naz. - L’ingegneria Sismica Ital., Siena, Italy, 1995: pp. 267-276 [In Italian].

[2] E. Galli, M. Savoia, C. Colla, D. Ferretti, Mechanical and Mineralogical Characterization of Mortar in Masonry Buildings Damaged by the 20-29th May Earthquake in Emilia, Key Eng. Mater. 624 (2014) 379-386. doi:10.4028/www.scientific.net/KEM.624.379.

[3] EN 1996-1-1:2005, Eurocode 6: Design of masonry structures - Part 1-1: General rules for buildings rules for reinforced and unreinforced masonry, (2005).

[4] EN 772-1:2011, Methods of test for masonry units - Part 1: Determination of compressive strength, (2011).

[5] L. Binda, G. Mirabella Roberti, C. Tiraboschi, S. Abbaneo, Measuring Masonry Material Properties, in: D.. Abrams, G.M. Calvi (Eds.), U.S.-Italy Work. Guidel. Seism. Eval. Rehabil. Unreinforced Mason. Build., Pavia, Italy, 1994: pp. 326-347. doi:10.1017/CBO9781107415324.004.

[6] L. Binda, G. Mirabella Roberti, C. Tiraboschi, Problemi di misura dei parametri meccanici della muratura e dei suoi componenti, in: La Mecc. Delle Murature Tra Teor. E Progett., Messina, Italy, 1996: pp. 45-54 [In Italian].

[7] EN 1015-11:2007, Methods of test for mortar for masonry - Part 11: Determination of flexural and co1npressive strength of hardened mortar, (2007).

[8] EN 459-1:2010, Building lime - Part 1: Definitions, specifications and conformity criteria, (2010).

[9] EN 12390-13:2013, Testing hardened concrete - Part 13: Determination of secant modulus of elasticity in compression, (2013).

[10] J. Válek, R. Veiga, Characterisation of mechanical properties of historic mortars: testing of irregular samples, in: C.A. Brebbia (Ed.), Struct. Stud. Repairs Maint. Herit. Archit. IX, WIT Press, 2005: pp. 
365-374.

[11] M. Drdácký, Non-Standard Testing of Mechanical Characteristics of Historic Mortars, Int. J. Archit. Herit. 5 (2011) 383-394. doi:10.1080/15583051003717788.

[12] A. Brignola, S. Frumento, S. Lagomarsino, S. Podestà, Identification of Shear Parameters of Masonry Panels Through the In-Situ Diagonal Compression Test, Int. J. Archit. Herit. 3 (2008) 52-73. doi:10.1080/15583050802138634.

[13] L. Pelà, P. Roca, A. Benedetti, Mechanical Characterization of Historical Masonry by Core Drilling and Testing of Cylindrical Samples, Int. J. Archit. Herit. (2015). doi:10.1080/15583058.2015.1077906.

[14] L. Pelà, A. Benedetti, D. Marastoni, Interpretation of Experimental Tests on Small Specimens of Historical Mortars, in: J. Jasieńko (Ed.), Struct. Anal. Hist. Constr., DWE, Wrocław, Poland, 2012: pp. 716-723.

[15] A. Benedetti, L. Pelà, Experimental Characterization of Mortar By Testing on Small Specimens, in: 15th Int. Brick Block Mason. Conf., Florianópolis, Brazil, 2012.

[16] F. Braga, M. Dolce, B. Filardi, A. Masi, D. Nigro, A test method to assess the shear strength of existing masonry structures - Theoretical basis and first experimental results, in: Int. Work. CNR-GNDT “Effectiveness Inject. Tech. Retrofit. Stone Brick Mason. Walls Seism. Areas,” Milan, Italy, 1992: pp. 204-227.

[17] B. Filardi, D. Liberatore, A. Masi, D. Nigro, Valutazione della Resistenza a Taglio di una Tipologia Muraria Tramite Prove su Pannelli, Carote e Triplette, in: La Mecc. Delle Murature Tra Teor. E Progett., Messina, Italy, 1996: pp. 75-84 [In Italian].

[18] A. Benedetti, L. Pelà, A. Aprile, Masonry Properties Determination Via Splitting Tests on Cores With a Rotated Mortar Layer, in: 8th Int. Semin. Struct. Mason., Instanbul, Turkey, 2008.

[19] C. Mazzotti, E. Sassoni, G. Pagliai, Determination of shear strength of historic masonries by moderately destructive testing of masonry cores, Constr. Build. Mater. 54 (2014) 421-431. doi:10.1016/j.conbuildmat.2013.12.039. 
[20] D.M. 14/01/2008, Approvazione delle nuove norme tecniche per le costruzioni, (2008) [In Italian].

[21] DIN 18555-9:1999, Testing of mortars containing mineral binders - Part 9: Hardened mortars. Determination of the mortar compressive strength in the bed joint, (1999).

[22] J. Henzel, S. Karl, Determination of Strength of Mortar in the Joints of Masonry by Compression Tests on Small Specimens, Darmstadt Concr. 2 (1987) 123-136.

[23] H.K. Hilsdorf, Investigation into the failure mechanism of brick masonry loaded in axial compression, Gulf Publishing Company, 1969.

[24] A.T. Vermeltfoort, R. Van Der Pluijm, Strength and Deformation Properties of Masonry to be Used in Computer Calculations, 9th Int. Brick Block Mason. Conf. (1991) 244-251. http://www.hms.civil.uminho.pt/ibmac/1991/244.pdf. 